\title{
Detecção e rastreamento de lábios em dispositivos móveis
}

\author{
Giseli de Araujo Ramos
}

\author{
DissertaÇÃo APRESENTADA \\ $\mathrm{AO}$ \\ Instituto de Matemática e Estatística \\ DA \\ Universidade De SÃo Paulo \\ PARA \\ OBTENÇÃO DO TÍTULO \\ $\mathrm{DE}$ \\ Mestre em CiênCias
}

Programa: Ciência da Computação

Orientador: Prof. Dr. Roberto Marcondes Cesar Jr.

Durante o desenvolvimento deste trabalho a autora recebeu auxílio financeiro da FINEP

São Paulo, outubro de 2012 


\section{Detecção e rastreamento de lábios em dispositivos móveis}

\footnotetext{
Esta versão da dissertação/tese contém as correções e alterações sugeridas pela Comissão Julgadora durante a defesa da versão original do trabalho, realizada em 29/10/2012. Uma cópia da versão original está disponível no Instituto de Matemática e Estatística da Universidade de São Paulo.
}

Comissão Julgadora:

- Prof. Dr. Roberto Marcondes Cesar Jr. (orientador) - IME-USP

- Prof. Dr. Carlos Hitoshi Morimoto - IME-USP

- Prof. Dr. Siome Klein Goldenstein - UNICAMP 


\section{Agradecimentos}

Em primeiro lugar, agradeço por ter uma família maravilhosa que sempre me deu apoio e me incentivou a aprender e seguir em frente com determinação, mesmo com as adversidades.

Agradeço ao orientador Roberto Marcondes César Jr. pela paciência, motivação e por acreditar no trabalho. À Cláudia Mendes de Oliveira, professora do IAG-USP por me dar apoio para ingressar no mestrado e possibilitar a conciliação do trabalho com os estudos no início do mestrado. Também agradeço aos colegas do projeto BTFI, em especial ao Bruno, ao Denis, ao Keith e ao Álvaro pela motivação e apoio dados durante a conciliação do trabalho com os estudos.

Também gostaria de agradecer aos colegas do grupo de visão computacional do IME, em especial ao Henrique, ao Jesús, à Andréa, à Silvia e à Jihan pelas discussões e troca de ideias. E aos professores Roberto Hirata Junior e Carlos Hitoshi Morimoto, pelos valiosos comentários na qualificação.

Aos meus amigos, pelo apoio moral e pelas discussões interessantes. Ao IME, pela acolhida. E meus agradecimentos à FINEP, FAPESP, CAPES e CNPq pelo suporte financeiro e por tornar possível esse projeto de mestrado. 


\section{Resumo}

RAMOS, Giseli de A. Detecção e rastreamento de lábios em dispositivos móveis. 2012. 60 f. Dissertação (Mestrado) - Instituto de Matemática e Estatística, Universidade de São Paulo, São Paulo, 2012.

A tecnologia tem estado presente cada vez mais no dia-a-dia e trouxe avanços notáveis para a área de visão computacional. Uma das áreas de visão, a detecção de características humanas, sempre foi importante para tarefas de reconhecimento, vigilância, controle e outras. Há um grande potencial de uso na área de acessibilidade, podendo ser benéfica para um grupo de pessoas com necessidades especiais, para proporcionar uma maior interação com o ambiente e com as pessoas. Uma dessas características, os lábios, é útil para o reconhecimento visual e/ou auditivo da fala e pode ser usada para aplicações em acessibilidade de deficientes auditivos e surdos, como por exemplo para a leitura labial.

Com a crescente popularização dos dispositivos móveis e avanços no hardware, além do custo cada vez mais acessível, torna-se possível a implementação de métodos rápidos e eficientes para detecção e seu posterior rastreamento. Assim, é possível o uso em tempo real nos dispositivos móveis. Esta dissertação descreve um sistema desenvolvido para a detecção e rastreamento da região dos lábios nesse contexto. A detecção da região dos lábios é feita pelo algoritmo de ViolaJones, com o diferencial do uso de conjuntos de imagens sintéticas para o treinamento e geração do detector proposto. O rastreamento é baseado no Camshift com modificações, um método de rastreamento de objeto por kernel.

A implementação é descrita em detalhes e são mostrados resultados obtidos por sequências gravadas em um dispositivo móvel. As sequências são capturadas em uma configuração não frontal, o que pode ser útil em aplicações específicas. Métricas baseadas no número de acertos, de erros e de falsos positivos são usadas para avaliar os resultados, além da taxa de quadros por segundo.

Palavras-chave: Acessibilidade, detecção de lábios, rastreamento. 


\section{Abstract}

RAMOS, Giseli de A. Lip detection and tracking in mobile devices. 2012. 60 f. Dissertação (Mestrado) - Instituto de Matemática e Estatística, Universidade de São Paulo, São Paulo, 2012.

Technology has been increasingly present and brought remarkable advances in the computer vision area. One of such areas, the detection and analysis of human behaviour, has been important for tasks of recognition, surveillance, control, and others. There is great potential for use in the area of accessibility, and it may benefit a group of people with special needs, to provide greater interaction with the environment and with people.

Facial feature detection plays a central role in this context. One of these features, the lips, is useful for speech recognition and can be used for applications in accessibility of deaf and hearing impaired, such as for lip reading.

With the growing popularity of mobile devices and advances in hardware, as well as more affordable costs, it becomes possible to implement rapid and reliable methods for lip detection and subsequent tracking. So it is possible the real-time use of mobile devices. This thesis describes a system developed for the detection and tracking lips region in this context.

The detection of the lips region is carried out by the Viola-Jones algorithm, but with the use of sets of synthetic images for the detector training and generation. Tracking is based on Camshift with modifications, a kernel-based object tracking method.

The implementation is described in details and results are shown from sequences recorded on a mobile device. The sequences are not captured on a frontal configuration, which may be useful in specific applications. Performance assessment in terms of metrics based on number of hits, errors and false positives are used to evaluate the results, in addition to the frame rate per second.

Keywords: accessibility, lip detection, tracking. 


\section{Sumário}

$\begin{array}{ll}\text { Lista de Abreviaturas } & \text { ix }\end{array}$

Lista de Figuras $\quad$ xi

Lista de Tabelas $\quad$ xiii

1 Introdução $\quad 1$

1.1 Motivação . . . . . . . . . . . . . . . . . . . . . . . . . 1

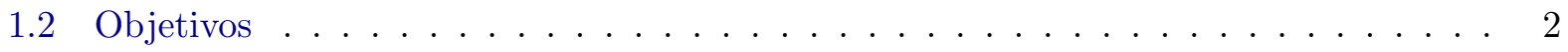

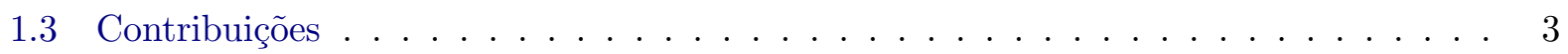

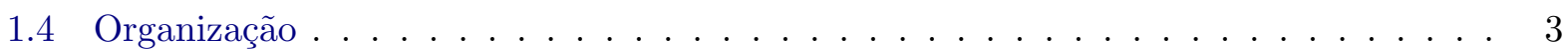

2 Trabalhos relacionados $\quad \mathbf{5}$

2.1 Tecnologias assistivas e dispositivos móveis . . . . . . . . . . . . . 5

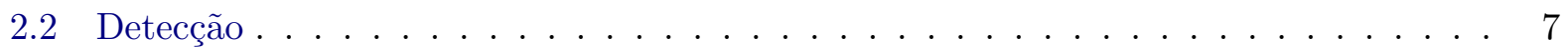

2.3 Rastreamento . . . . . . . . . . . . . . . . . . . . 9

3 Sistema proposto $\quad 11$

3.1 Visão geral . . . . . . . . . . . . . . . . . . . . . . . . . 11

3.2 Deteç̧ão . . . . . . . . . . . . . . . . . . . . . . . . 12

3.2 .1 Características Haar e Imagem Integral . . . . . . . . . . . . . . . . . 12

3.2.2 Algoritmo de AdaBoost . . . . . . . . . . . . . . . . . . . . . . 14

3.2 .3 Cascata de classificadores . . . . . . . . . . . . . . . . . . 15

3.3 Geração dos conjuntos de treinamento . . . . . . . . . . . . . . . . . . . 16

3.4 Rastreamento . . . . . . . . . . . . . . . . . . . . . . . . 19

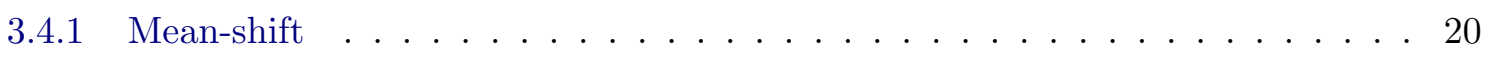

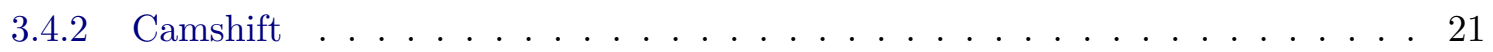

3.4 .3 Modificações . . . . . . . . . . . . . . . . . . . . . . 22

3.4.4 Espaço de cores utilizados no rastreamento . . . . . . . . . . . . . . . 24

4 Resultados experimentais $\quad \mathbf{2 7}$

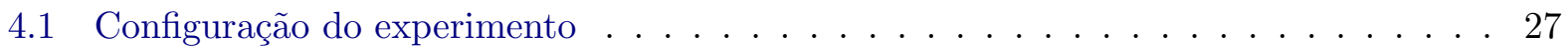

4.1 .1 Implementação . . . . . . . . . . . . . . . . . . . . . 27

4.1 .2 Dados do treinamento e teste . . . . . . . . . . . . . 28

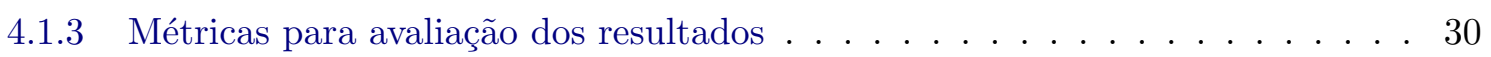

4.2 Resultados da Detecção . . . . . . . . . . . . . . . . . . . . . . 31 


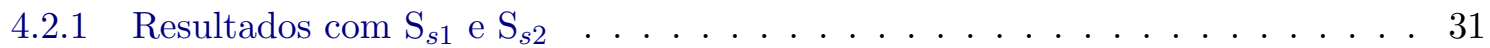

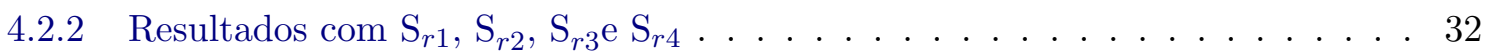

4.3 Rastreamento . . . . . . . . . . . . . . . . . . . 34

4.4 Implementação em um dispositivo móvel . . . . . . . . . . . . . . . . 36

4.5 Discussão dos resultados . . . . . . . . . . . . . . . . . . 36

5 Conclusão $\quad 39$

5.1 Comentários finais . . . . . . . . . . . . . . . . . 39

5.2 Trabalhos futuros . . . . . . . . . . . . . . . . . . . . 40

$\begin{array}{ll}\text { Referências Bibliográficas } & 41\end{array}$ 


\title{
Lista de Abreviaturas
}

\author{
FPS Taxa de quadros por segundo (Frame rate per second) \\ RGB Modelo de cor RGB (Red, Green and Blue) \\ HSV Modelo de cor HSV (Hue, Saturation and Value) \\ ROI Região de interesse (Region of Interest) \\ AdaBoost Técnica de aprendizado de máquina (Adaptive Boosting) \\ Camshift Método de rastreamento (Continuously Adaptive Mean Shift) \\ IOU Métrica de avaliação de sobreposição de duas regiões de interesse (Intersection Over Union)
}




\section{Lista de Figuras}

1.1 Celular Nokia N97 com tela e câmera inclinada. Fonte: Nokia Conversations. . . . 2

2.1 Exemplos de publicações especializadas e de acessibilidade. . . . . . . . . . . . . . 6

2.2 Notícia de investimento em acessibilidade (extraída de notícia da FINEP do dia 17/11). 6

2.3 Demonstração no N900. Imagem extraída do artigo de Tresadern et al. (2011). . . . 8

2.4 Etapas da detecção. Imagem extraída do artigo de Shin et al. (2011). . . . . . . . . 8

2.5 Um exemplo de uso e o diagrama de funcionamento do TLD. Imagens extraídas de Kalal et al. (2010a) e Kalal et al. (2010b) (poster). . . . . . . . . . . . . . . . . . . . 10

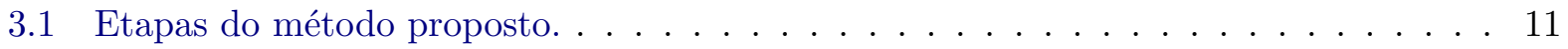

3.2 Características retangulares. . . . . . . . . . . . . . . . . . . 12

3.3 Aplicando as características na imagem (extraída do artigo de Viola e Jones (2002)). 13

3.4 Imagem integral . . . . . . . . . . . . . . . . . . . . . . . . . 13

3.5 Cálculo da característica. Imagem adaptada de Viola e Jones (2002) . . . . . . . . . 13

3.6 Cascata. . . . . . . . . . . . . . . . . . . . . . . 15

3.7 Configuração de uso. . . . . . . . . . . . . . . . . . . . . . 17

3.8 Planos de rotação do modelo. . . . . . . . . . . . . . . . . . . . . . . 17

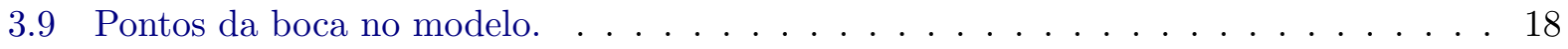

3.10 Exemplos do primeiro conjunto de imagens sintéticas. . . . . . . . . . . . . . 18

3.11 Exemplos do segundo conjunto de imagens sintéticas. . . . . . . . . . . . . . . . . 19

3.12 Exemplos de imagens negativas de Seo (2008). . . . . . . . . . . . . . . . . 19

3.13 Exemplos de imagens negativas de autoria própria. . . . . . . . . . . . . . . . 19

3.14 Um passo do mean-shift (figura adaptada de notas de aula de Ukrainitz e Sarel (2004)). 20

3.15 Operações realizadas com a imagem de retroprojeção. . . . . . . . . . . . . . . 22

3.16 Operações realizadas no canal Q. A máscara binária é obtida por limiarização, com valor limite de $35 \%$ do maior valor do canal Q . . . . . . . . . . . . 23

3.17 Algoritmo Camshift original. . . . . . . . . . . . . . . . . . . . . . 23

3.18 Algoritmo Camshift modificado. . . . . . . . . . . . . . . . . . . 23

4.1 Amostra de 5 quadros das sequências usadas nos experimentos. . . . . . . . . . . . 28

4.2 Modelos usados no treinamento e no teste. . . . . . . . . . . . . . . . . . . . 29

4.3 Planos de rotação do modelo. . . . . . . . . . . . . . . . . . . . 30

4.4 Exemplos de detecções em 5 quadros de cada sequência. . . . . . . . . . . . . . . . 33

4.5 Exemplos de rastreamento em 5 quadros de cada sequência. . . . . . . . . . . . . . 35 
4.6 Imagens capturadas do dispositivo móvel. (a) Um exemplo de detecção do detector D3 e (b) rastreamento em um dos quadros subsequentes à detecção. . . . . . . . . . . 36 


\section{Lista de Tabelas}

4.1 Sumário da avaliação de desempenho. . . . . . . . . . . . . . . . . . 31

4.2 Tabela com os valores de precisão, revocação e acurácia para os resultados com os detectores D1 e D2 no conjunto $\mathrm{S}_{s 1} \ldots \ldots \ldots \ldots \ldots \ldots \ldots \ldots$

4.3 Tabela com os valores de precisão, revocação e acurácia para os resultados com os detectores D1 e D3 no conjunto $\mathrm{S}_{s 2} \ldots \ldots \ldots \ldots \ldots \ldots \ldots \ldots$

4.4 Tabela com os valores de precisão, revocação e acurácia para a sequência $\mathrm{S}_{r 1} \mathrm{com}$ fator de escala de $1,05 . \ldots \ldots \ldots \ldots \ldots \ldots$

4.5 Tabela com os valores de precisão, revocação e acurácia para a sequência $\mathrm{S}_{r 2}$ com fator de escala de $1,05 . \ldots \ldots \ldots \ldots \ldots$

4.6 Tabela com os valores de precisão, revocação e acurácia para a sequência $\mathrm{S}_{r 3} \mathrm{com}$

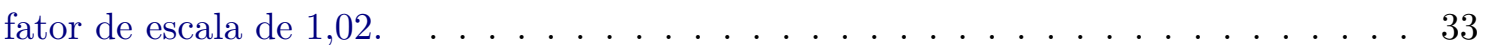

4.7 Tabela com os valores de precisão, revocação e acurácia para a sequência $\mathrm{S}_{r 4}$ com fator de escala de $1,05 . \ldots \ldots \ldots \ldots \ldots$

4.8 Tempo médio da detecção em milissegundos. As sequências 1, 2 e 4 foram testadas com fator de escala 1,05 e a sequência 3 com fator de escala $1,02 . \quad$. . . . . . . . . 34

4.9 Tabela com os valores de precisão, revocação e acurácia para as sequências. . . . . . 34 


\section{Capítulo 1}

\section{Introdução}

O reconhecimento automático da fala é uma tecnologia importante, presente nos dispositivos móveis. Programas como o Siri ${ }^{\circledR}$ para o iPhone ${ }^{\circledR}$ e o Vlingo ${ }^{\circledR}$ para Android ${ }^{\mathrm{TM}}$ já são populares. Um dos desafios atuais é melhorar a taxa de reconhecimento do som, e um dos modos é fazer uso do reconhecimento visual da fala. Assim, a detecção de características da face, mais especificamente, dos lábios, pode auxiliar e influir de modo positivo na taxa de reconhecimento da fala.

Essas tecnologias podem prover acessibilidade para um grupo de pessoas com necessidades especiais, como os deficientes auditivos, visuais e físicos, para facilitar suas interações com o ambiente e com as pessoas, por meio do dispositivo móvel. Há um crescente interesse da comunidade de visão computacional em prover soluções de acessibilidade, que pode ser demonstrado pelas conferências que vêm ocorrendo a cada ano, como o Workshop on Computer Vision Applications for the Visually Impaired, integrante do CVPR, uma das mais importantes conferências em visão, a série de conferências patrocinadas pela ACM, ASSETS (The International ACM SIGACCESS Conference on Computers and Accessibility) e as conferências ICCHP (International Conference on Computers Helping People with Special Needs) e CVHI (Conference and Workshop on Assistive Technology for People with Vision and Hearing Impairments).

Há ainda publicações especializadas, como a ACM Transactions on Accessible Computing ${ }^{1}$, o periódico Technology and Disability ${ }^{2}$ e o livro Visual Speech Recognition (Liew e Wang (2008)).

Para que se possa realizar o reconhecimento visual da fala, é necessário localizar e caracterizar os lábios. Um sistema de leitura labial geralmente se compõe das seguintes etapas: detecção, rastreamento, extração de características e reconhecimento dos visemas (informação visual dos lábios, língua e dentes, de acordo com Fisher (1968)). Este trabalho de mestrado se concentra nas etapas de detecção e de rastreamento da região dos lábios.

\subsection{Motivação}

A detecção e o rastreamento da região dos lábios usualmente é feita com a câmera apontando para o usuário. Em determinadas situações, como reuniões ou conferências, o uso de uma abordagem não intrusiva pode ser desejável, ao invés de apontar diretamente para as pessoas com o dispositivo móvel. Nesta configuração, o dispositivo móvel pode estar localizado na mesa e com

\footnotetext{
${ }^{1}$ Página principal: http://www.gccis.rit.edu/taccess/index.html

${ }^{2}$ Página principal do periódico: http://www.iospress.nl/journal/technology-and-disability/
} 


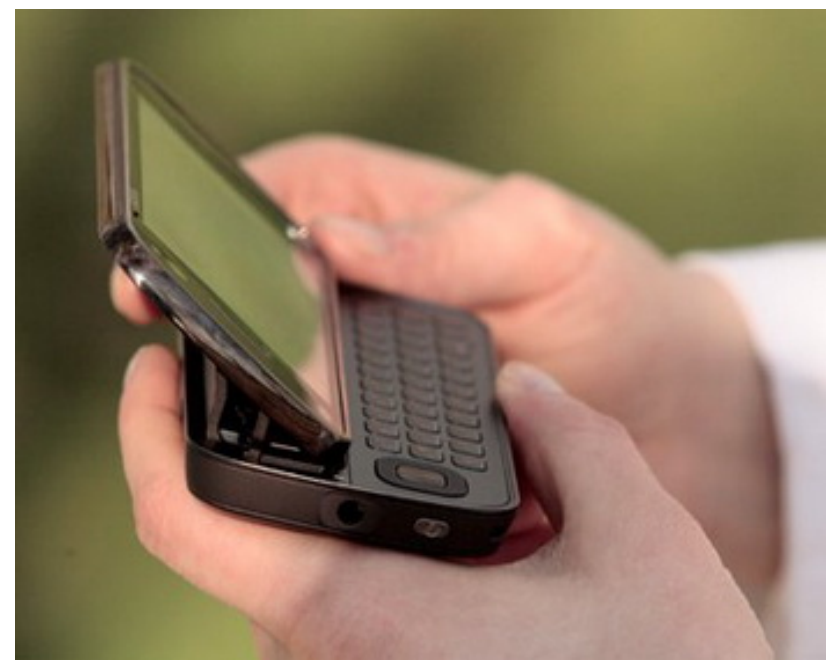

Figura 1.1: Celular Nokia N97 com tela e câmera inclinada. Fonte: Nokia Conversations.

uma certa inclinação. A figura 1.1 mostra um possível uso do celular N97. Nesta configuração, abordagens usuais de detecção e rastreamento da boca não se aplicam, por serem otimizadas para posições frontais. Trabalhos como o de Lucey et al. (2008) e Estellers e Thiran (2012), que tratam da multivisão, foram feitos para lidar com rotações específicas da face e aproximadamente no mesmo plano da visada do usuário. Não lidam com possíveis usos não-intrusivos a partir de dispositivos móveis.

Um método bem sucedido de detecção e que usualmente fornece bons resultados é o uso do framework de detecção de Viola e Jones (2002). Para o uso do método, é necessário utilizar classificadores, já disponíveis na biblioteca de visão computacional OpenCV. Esses classificadores são treinados para detectar a face e os lábios em uma posição frontal ou próxima da frontal. Para outras posições, não há detectores disponíveis, sendo necessário um treinamento prévio das características desejadas nas mais diversas posições, como quando o dispositivo móvel se localiza abaixo da face do usuário. Uma desvantagem do método é a sua etapa de treinamento, que pode ser dispendiosa, pois exige a rotulação manual de milhares de fotos com a característica desejada, nesse caso, os lábios. Para otimizar a etapa de treinamento, esta dissertação explora uma estratégia alternativa através da geração automática dos conjuntos de treinamento, composto por imagens sintéticas oriundas do trabalho de Mattos et al. (2010).

Após a realização de uma detecção bem-sucedida, é necessário o acompanhamento da característica de interesse. Isso pode ser feito por detecções sucessivas ou uso de correspondências por pontos, região ou contorno, três categorias usuais de rastreamento de acordo com Yilmaz et al. (2006). Neste trabalho, explora-se o método Camshift para o rastreamento, pois o foco é o rastreamento da região da boca.

\subsection{Objetivos}

O objetivo do trabalho nesse mestrado é o desenvolvimento de metódos de detecção e rastreamento da região dos lábios para sua utilização em dispositivos móveis em diferentes posições da face, não sendo necessário que o usuário tenha que se posicionar com a face exatamente à frente da câmera. 


\subsection{Contribuições}

As principais contribuições são listadas a seguir:

- Proposição e implementação de um sistema de detecção da região dos lábios, conforme indicado nos objetivos;

- Geração automática de conjunto de treinamento para o detector de lábios usando imagens sintéticas;

- Validação do detector treinado pelas imagens sintéticas;

- Validação do rastreamento com o uso do Camshift (Continuously Adaptive Mean Shift) com modificações e uso do espaço de cor YIQ;

- Criação de um aplicativo que pode ser executado em dispositivos móveis para detecção e rastreamento dos lábios.

\subsection{Organização}

O capítulo 2 discute a importância da acessibilidade e mostra os trabalhos atuais de detecção e rastreamento de lábios. O capítulo 3 detalha o método de detecção utilizado e o uso de imagens sintéticas como conjunto de treinamento. Além disso descreve o método utilizado no rastreamento. A implementação e os resultados dos métodos propostos são mostrados no capítulo 4. Conclusões são feitas no capítulo 5, bem como sugestões para projetos futuros. 


\section{Capítulo 2}

\section{Trabalhos relacionados}

\subsection{Tecnologias assistivas e dispositivos móveis}

Há um crescente interesse da comunidade de visão computacional em oferecer soluções para acessibilidade. Esse interesse pode ser demonstrado pela organização de conferências e workshops, mencionadas a seguir:

- Workshop on Computer Vision Applications for the Visually Impaired, integrante do CVPR, uma das mais importantes conferências em visão;

- A série de conferências patrocinadas pela ACM, ASSETS: The International ACM SIGACCESS Conference on Computers and Accessibility ${ }^{1}$;

- ICCHP (International Conference on Computers Helping People with Special Needs) ${ }^{2}$;

- CVHI (Conference and Workshop on Assistive Technology for People with Vision and Hearing Impairments $)^{3}$.

Publicações especializadas já foram lançadas, como por exemplo a ACM Transactions on Accessible Computing ${ }^{4}$, o periódico Technology and Disability ${ }^{5}$ e o livro Visual Speech Recognition (Liew e Wang (2008)). As publicações são mostradas na figura 2.1. Os projetos nesta área de acessibilidade têm recebido investimentos e continuarão a receber nos próximos anos, como pode ser demonstrado pela notícia da FINEP (figura 2.2), em que o governo forneceu uma verba dedicada a projetos de acessibilidade no final de 2011.

Os trabalhos relacionados especificamente a dispositivos móveis e acessibilidade têm se concentrado em prover soluções para deficientes físicos e visuais (navegação e informação do ambiente), como os trabalhos de Manduchi et al. (2010) e Tekin et al. (2011). Um artigo dos autores Manduchi e Coughlan (2012) menciona os principais trabalhos já feitos para acessibilidade de deficientes visuais. Trabalhos dedicados aos surdos e deficientes auditivos se concentram em soluções relacionadas à linguagem de sinais (Cherniavsky et al. (2009)). Para o reconhecimento audiovisual

\footnotetext{
${ }^{1}$ Página principal da conferência: http://wwww.sigaccess.org/conferences/assets/

${ }^{2}$ Página principal da conferência: http://www.icchp.org/

${ }^{3}$ Página principal da conferência: http://www.elec.gla.ac.uk/Events_page/CVHI/cvhi/

${ }^{4}$ Página principal: http://www.gccis.rit.edu/taccess/index.html

${ }^{5}$ Página principal do periódico: http://www.iospress.nl/journal/technology-and-disability/
} 


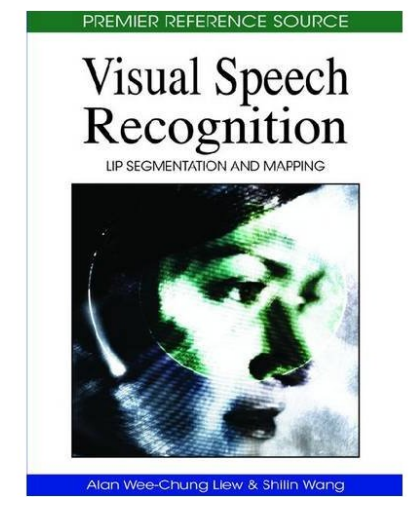

(a) Visual Speech Recognition

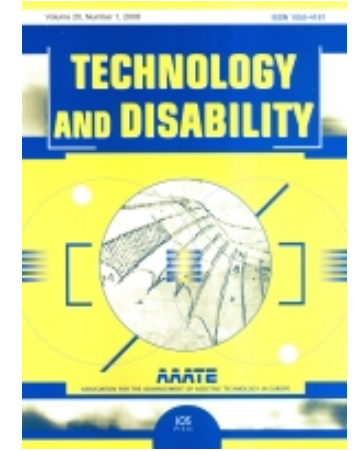

(b) Technology and Disability

Figura 2.1: Exemplos de publicações especializadas e de acessibilidade.

\section{Notícias}

Dilma anuncia investimento de $\mathbf{R} \$ 150$ milhōes da FINEP para tecnologias assistivas

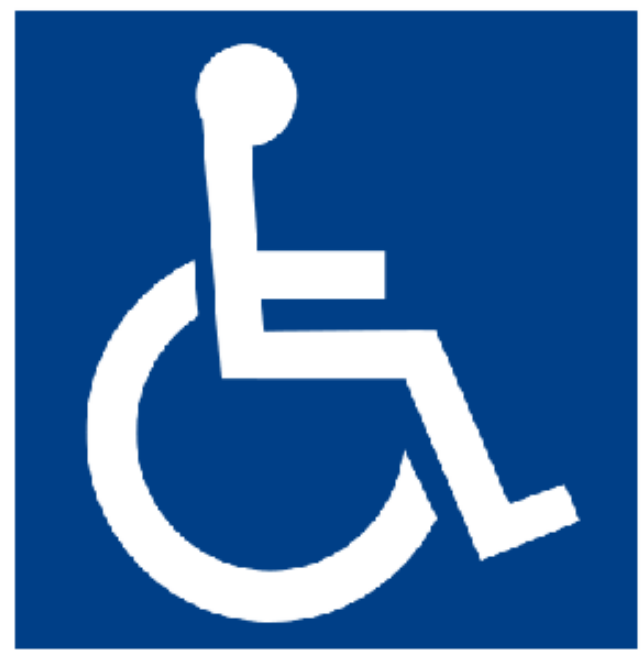

Nesta quinta-feira (17/11), a presidenta Dilma Rousseff anunciará o Plano Nacional dos Direitos das Pessoas com Deficiência, conhecido também como Viver sem Limite. Em consonância com as diretrizes do governo federal, a Financiadora de Estudos e Projetos (FINEP) vai destinar R\$ 150 milhōes de seu orçamento a projetos inovadores que tenham como foco a inclusão de pessoas com deficiência. Até o fim deste ano, será lançada a primeira chamada pública, no valor de R\$20

Figura 2.2: Notícia de investimento em acessibilidade (extraída de notícia da FINEP do dia 17/11). 
ou visual apenas da fala, ainda há poucos trabalhos específicos para dispositivos móveis e embarcados, como por exemplo os trabalhos de Kim et al. (2009) e Shin et al. (2011). A grande maioria das soluções mencionadas nesta seção foram implementadas em computadores, mas passíveis de serem convertidas para o ambiente móvel, com os devidos ajustes.

\subsection{Detecção}

O uso de aplicativos móveis para detecção de faces e suas características faciais tem crescido nos últimos anos. A detecção representa um desafio para os dispositivos móveis, pois as condições em que há uso do dispositivo geralmente não são controladas, podendo ter influências da iluminação e da posição do usuário. Os métodos de detecção usualmente são divididos em três categorias principais: detecção por uso direto da informação da imagem (pixels), detecção por modelos e detecção híbrida, combinando informação da imagem e modelos.

Métodos baseados na imagem usam diretamente o valor do pixel como informação, tirando proveito do espaço de cor da imagem. Esse tipo de método pode não ser robusto por ser sujeito a fatores do ambiente, como iluminação. Wark et al. (1998) propôs usar a razão R/G e usar limiares inferiores e superiores nessa razão. Sua desvantagem é que os limiares podem variar de acordo com o ambiente e com as faces, sendo determinados experimentalmente. Vários trabalhos sugerem transformações do espaço RGB de cores para outros espaços de cores que minimizam a influência da iluminação. Thejaswi e Sengupta (2008) sugere o uso do YIQ e Hsu et al. (2002) sugere a utilização do YCrCb na região de interesse. Eveno et al. (2004) sugere a adoção da pseudo-matiz (pseudohue, de Hurlbert e Poggio (1988)), pois a diferença entre vermelho e verde é maior para os lábios do que para a pele, sendo então mostrada na forma de uma razão entre vermelho e a soma do vermelho com o verde, para destacar essa diferença.

Abordagens que usam modelos exigem um conhecimento prévio do formato dos lábios e podem ser robustas, mas em contrapartida, são dispendiosas computacionalmente e frequentemente exigem um treinamento prévio, em comparação com métodos baseados em imagem, pois envolvem a computação de minimização de uma função custo.

Modelos de aparência ativa (AAM - Active Appearance Models) amostram pixels da imagem em uma região definida por um conjunto de pontos de controle (definidos por parâmetros de um modelo de forma) e alimentam os dados amostrados da imagem em um regressor que prevê atualizações incrementais para se ajustar aos parâmetros da forma. O processo é repetido iterativamente até a convergência ou um limite definido. Tresadern et al. (2011) utiliza esta abordagem, que foi implementada em um celular Nokia 900 (figura 2.3).

Outros métodos de modelos sugeridos são as snakes, que podem atingir resultados razoáveis, mas têm a desvantagem de dependerem de uma inicialização apropriada, usualmente manual, e não serem adequadas para detecção de cantos em regiões de baixo gradiente. Eveno et al. (2004) sugeriu o uso de jumping snakes para superar a limitação da segmentação em regiões de baixo gradiente. Guitarte Perez et al. (2005) propôs um algoritmo de baixo custo para sistemas embarcados, em que se baseia em um modelo geométrico da face para encontrar os lábios, encontrando relações entre os blobs das sobrancelhas e dos lábios.

Abordagens híbridas combinam as informações da imagem com os modelos, primeiro com a utilização de técnicas baseadas em cores para uma estimativa rápida e aproximada da região dos 


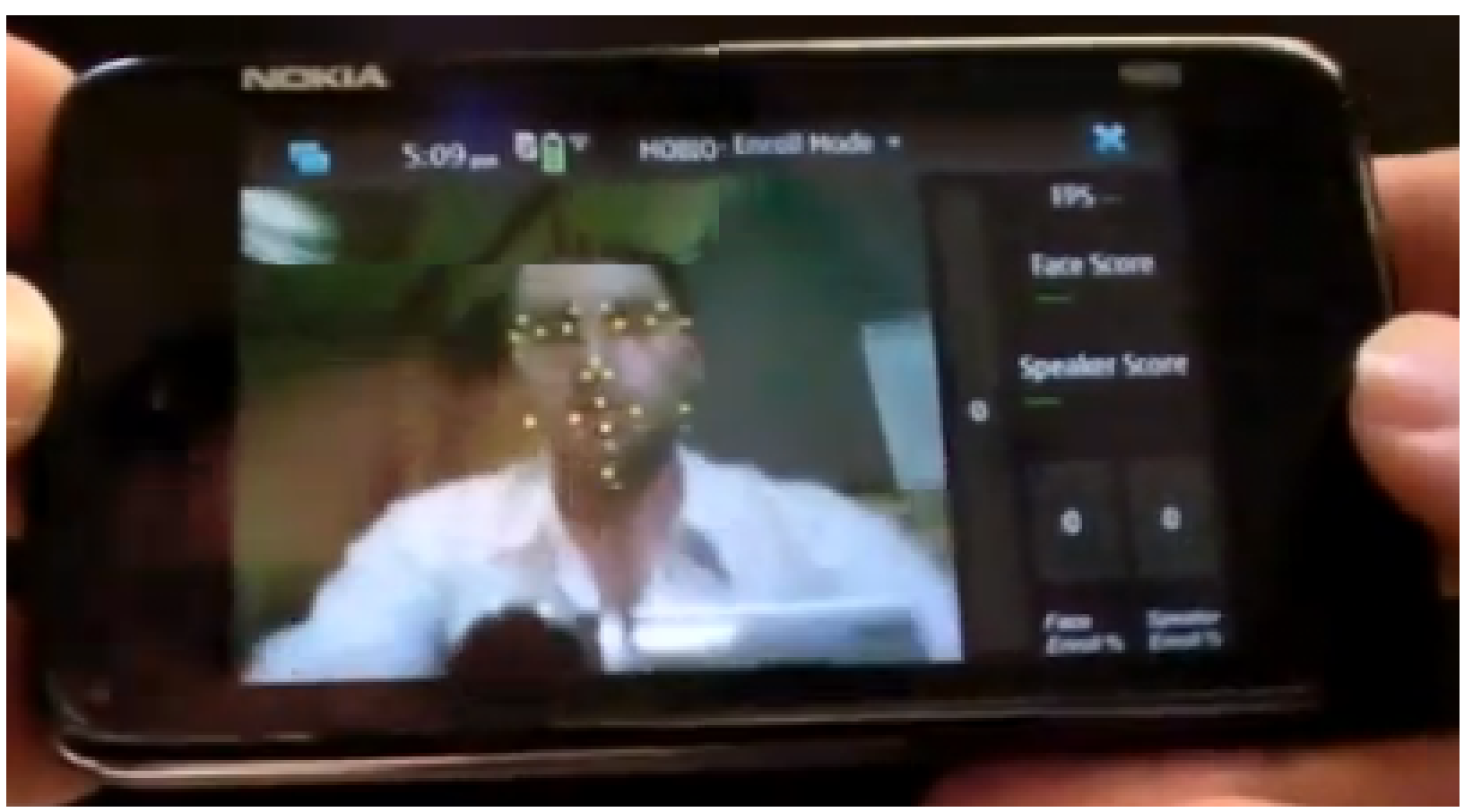

Figura 2.3: Demonstração no N900. Imagem extraída do artigo de Tresadern et al. (2011).

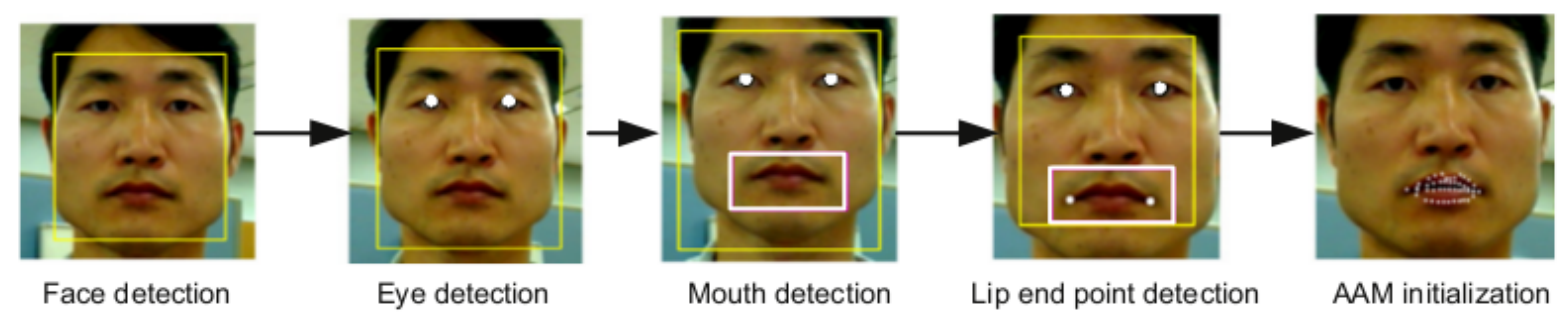

Figura 2.4: Etapas da deteç̧ão. Imagem extraída do artigo de Shin et al. (2011).

lábios e posteriormente a aplicação de um modelo para a obtenção dos contornos exatos dos lábios. O trabalho de Bouvier et al. (2007) sugere o uso de uma transformada de cor e depois o uso de snakes, para detectar os contornos da parte superior e inferior dos lábios.

Alguns dos métodos mencionados, como o de Tresadern et al. (2011) e Kim et al. (2009), foram implementados especificamente para dispositivos móveis. Outros, como o trabalho de Shin et al. (2011) (figura 2.4) e Guitarte Perez et al. (2005), foram implementados em sistemas embarcados, para uso em carros.

Os métodos de detecção mencionados se concentram na posição frontal. Métodos de detecção em perfil ou em uma posição inclinada são mencionados nos trabalhos de Lucey et al. (2008), Kumar et al. (2007) e Estellers e Thiran (2012). Estellers e Thiran (2012) gera imagens frontais virtuais, a partir de imagens não-frontais, inspirada em técnicas de reconhecimento de faces invariantes à pose.

Bancos de dados de faces sintéticas a partir de texturas de faces reais foram propostos para treino e avaliação de expressões faciais, mas não são utilizados para a criação de detectores de características faciais, como os lábios. O banco de dados GavaDB (Moreno e Sanchez (2004)) fornece imagens das faces sintéticas, mas as animações e os gabaritos não são fornecidos, sendo necessária a 
definição manual destes. O banco de dados proposto no trabalho de Yin et al. (2006), o BU-3DFE, fornece texturas das faces reais com gabarito, mas não oferece animações e nem imagens. $\mathrm{O}$ trabalho de Queiroz et al. (2010) sugere a criação de um banco de dados que fornece imagens sintéticas com gabaritos e animações. O banco de dados não é público e não está disponível.

Com a limitação da disponibilidade do banco de dados, optou-se pelo uso de uma abordagem do trabalho de Mattos et al. (2010), cujo código foi disponibilizado para este projeto e permite a geração automática de imagens e animações com gabaritos.

\subsection{Rastreamento}

Após uma detecção inicial dos lábios, é necessário o uso de uma técnica para acompanhar a trajetória temporal nos quadros seguintes, que pode ser feito por uma nova detecção ou por rastreamento de pontos específicos ou uma região dos lábios. O rastreamento pode se tornar um desafio, principalmente em ambientes não controlados. De acordo com Yilmaz et al. (2006) há três categorias principais de métodos de rastreamento: rastreamento por correspondências entre os pontos, rastreamento de kernel e rastreamento por contornos.

Rastreamento por pontos se baseia em métodos que encontrem correspondências dos pontos em quadros consecutivos. As correspondências são estimadas se baseando no estado anterior do objeto. Exemplos são o filtro de Kalman e filtro de partículas.

Pelo método de kernel, o rastreamento se dá pela forma e aparência do objeto. A função do kernel pode ser, por exemplo, um modelo de retângulo ou elipse associado a um histograma e o rastreamento é feito calculando o movimento do kernel em uma sequência de quadros. Métodos como o rastreador de características de Kanade-Lucas-Tomasi (KLT), Mean-Shift e Camshift usam esta abordagem.

O rastreamento de contornos é feito pela estimativa da região do objeto em uma sequência de quadros. Esse método usa a informação contida dentro da região do objeto, que pode ser na forma de modelos de forma ou mapas de bordas. A partir dessa informação, os contornos são rastreados por correspondência de forma ou cálculo de evolução dos contornos.

O trabalho de Kalal et al. (2009) sugere, como rastreador de objetos, o chamado TLD, um algoritmo que aprende em tempo real a aparência do objeto, após a definição de uma ROI em torno do objeto. A sigla TLD significa: Track, Learn and Detect, pois em simultâneo rastreia o objeto, aprende sua aparência e o detecta, caso apareça nos quadros seguintes. Esse algoritmo exige a definição manual da ROI, além de exigir um alto custo computacional. A figura 2.5 demonstra seu uso em faces.

Outro trabalho Wang et al. (2010) sugere o uso de filtro Kalman, em que auxilia o detector de lábios, estimando o centro da região dos lábios no próximo estado e posteriormente, faz uma previsão, baseando-se no estado estimado anteriormente.

No caso de rastreamento por pontos específicos dos lábios, o trabalho de Tresadern et al. (2011) e Shin et al. (2011) usam modelos de aparência ativa, que consiste numa combinação linear das formas-base com a forma média. Para a criação da forma-base, deve-se realizar um treinamento prévio com o objeto de interesse, definindo manualmente os pontos no objeto. Os modelos treinados não levam em consideração rotações fora do plano ou posições não-frontais da face. 

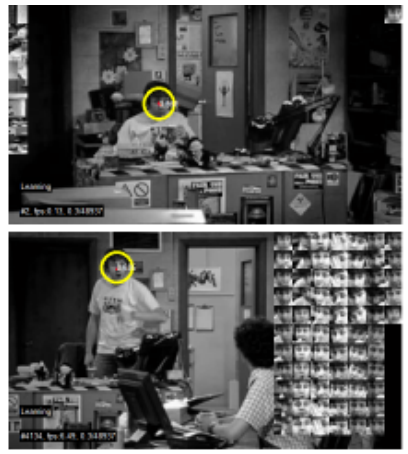

(a) Exemplo de uso do TLD em um vídeo.

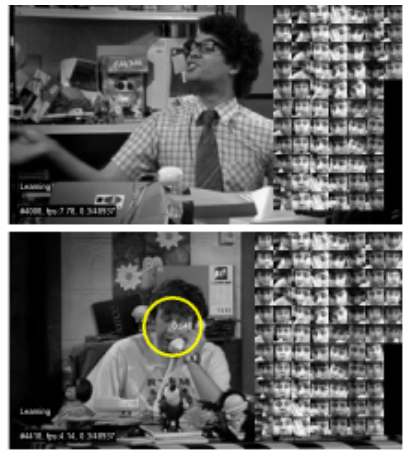

Figura 2.5: Um exemplo de uso e o diagrama de funcionamento do TLD. Imagens extraídas de Kalal et al. Figura 2.5: Um exemplo de uso e o diagr
(2010a) e Kalal et al. (2010b) (poster).

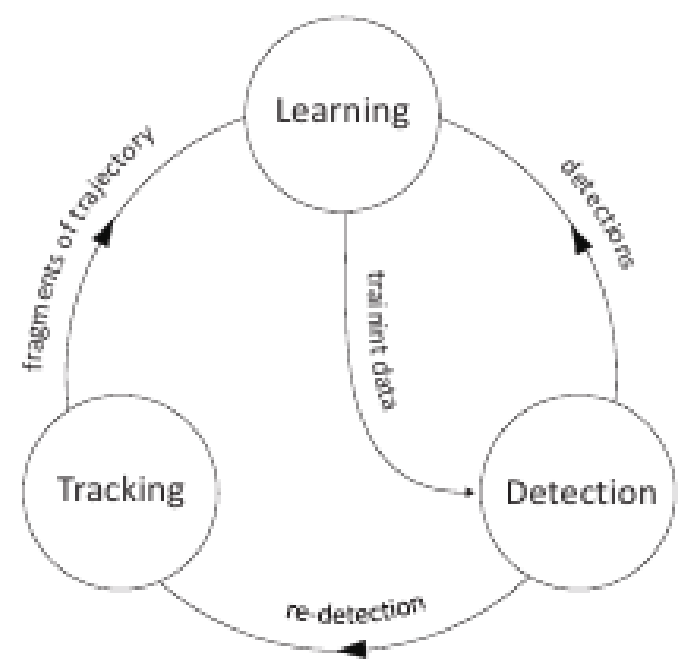

(b) Diagrama do TLD. 


\section{Capítulo 3}

\section{Sistema proposto}

\subsection{Visão geral}

A figura 3.1 mostra uma visão geral do método proposto, com as etapas de detecção e rastreamento. Na etapa da detecção, se faz uso do algoritmo de Viola-Jones, baseado em quatro conceitos centrais: características Haar, baseadas nas wavelets de mesmo nome; imagem integral; o método de aprendizado de máquina AdaBoost e uma combinação dos classificadores obtidos pelo AdaBoost em uma estrutura de cascata. O resultado da deteç̧ão é uma ROI retangular englobando a característica de interesse, os lábios.

A detecção é realizada em laço até a ocorrência de um resultado com o objeto de interesse. Assim o laço é terminado e procede-se à etapa de rastreamento. A ROI da etapa de detecção é repassada para essa etapa de rastreamento, que utiliza o algoritmo Camshift. Os passos desse algoritmo são: (1) definição de uma janela de busca; (2) cálculo da distribuição de probabilidade; (3) iteração do mean-shift; (4) centralização da janela de busca e cálculo da nova escala; (5) volta ao passo (2). No passo (1), a janela de busca é definida pela ROI que foi repassada pelo método de detecção. Para o cálculo da distribuição de probabilidade (passo (2)), usa-se o canal matiz do espaço de cor HSV, transformado do espaço RGB normalizado. O espaço YIQ também é usado, para uma operação AND com o histograma de probabilidade.

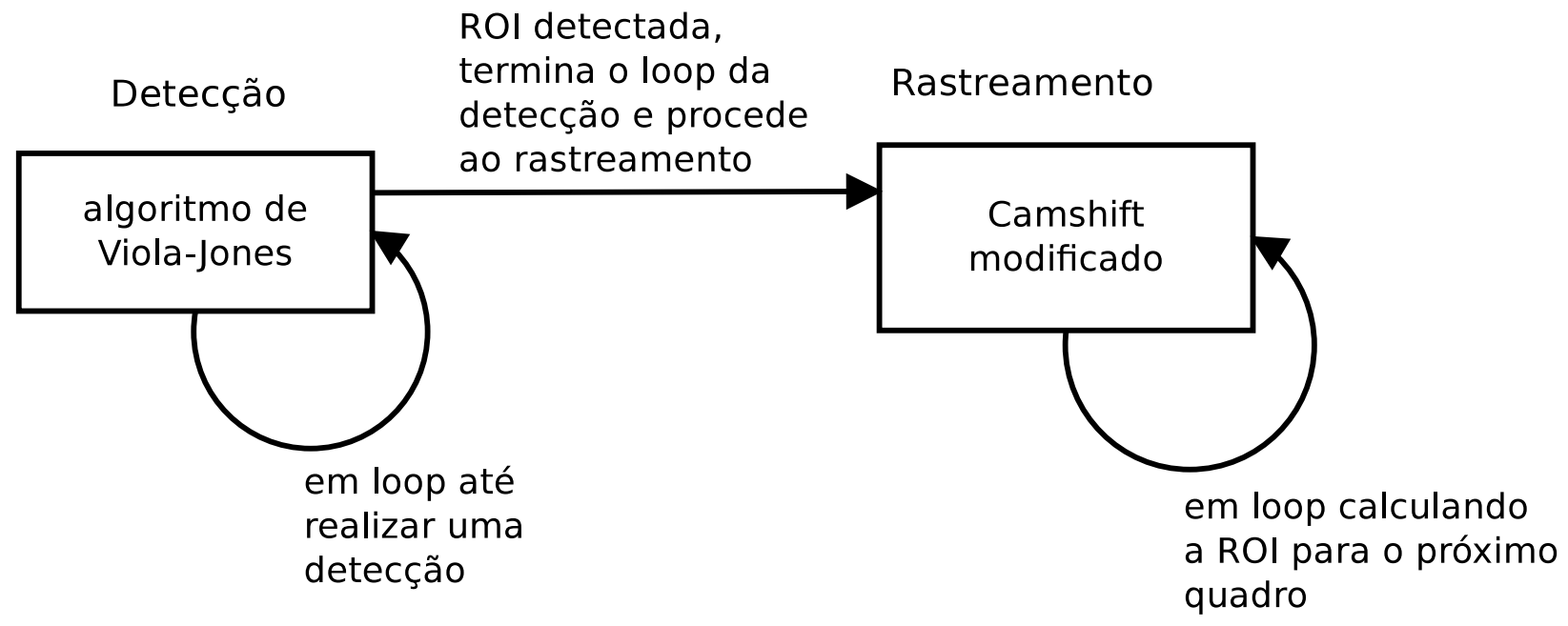

Figura 3.1: Etapas do método proposto. 


\subsection{Detecção}

Um método amplamente usado para detecção de objetos foi proposto por Viola e Jones (2002), que é utilizado nesse trabalho. Uma das razões para sua popularidade é a possibilidade de treinar o detector para diferentes classes de objetos. Viola e Jones (2002) usa quatro conceitos centrais: características simples, chamadas de características Haar; introdução do conceito de imagem integral; o método de aprendizado de máquina AdaBoost e um classificador em cascata para combinação de características.

\subsubsection{Características Haar e Imagem Integral}

As características (features) usadas no framework de detecção de Viola-Jones são chamadas de Haar, um conjunto de características retangulares de duas dimensões (2D). Elas foram baseadas nas wavelets Haar, cuja função-base é descrita na equação 3.1 .

$$
\psi(t)=\left\{\begin{array}{lc}
1 & 0 \leq t \leq 1 / 2 \\
-1 & 1 / 2 \leq t \leq 1 \\
0 & \text { caso contrário. }
\end{array}\right.
$$

Na detecção de objetos usualmente há três tipos de características Haar: características com 2 retângulos, 3 retângulos e 4 retângulos, exemplificados na figura 3.2.

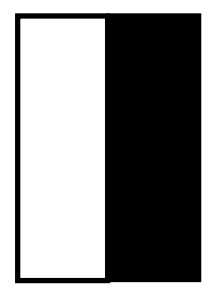

\section{2 retângulos}

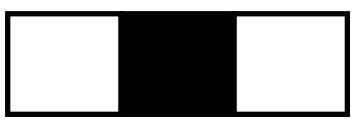

\section{3 retângulos}

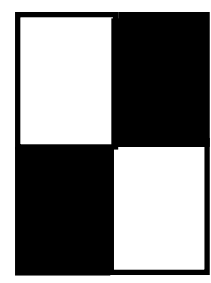

\section{4 retângulos}

Figura 3.2: Exemplos de características retangulares.

Quando essas características são aplicadas na imagem (como mostrado na figura 3.3), o valor da característica é determinado pela diferença entre a soma dos pixels na região branca e a soma dos pixels na região escura. Para uma computação rápida dos valores das características, em vez do uso da imagem original ao aplicar as características, usa-se o conceito de imagem integral (figura 3.4). O valor em uma coordenada $(x, y)$ da imagem integral, sendo que $x$ representa a coluna e $y$ representa a linha, é dado pela soma dos pixels acima e à esquerda de $x, y$, de maneira inclusiva, de acordo com a fórmula: 


$$
i i(x, y)=\sum_{x^{\prime} \leq x, y^{\prime} \leq y} i\left(x^{\prime}, y^{\prime}\right)
$$

onde $i i(x, y)$ é a imagem integral e $i(x, y)$ é a imagem original.

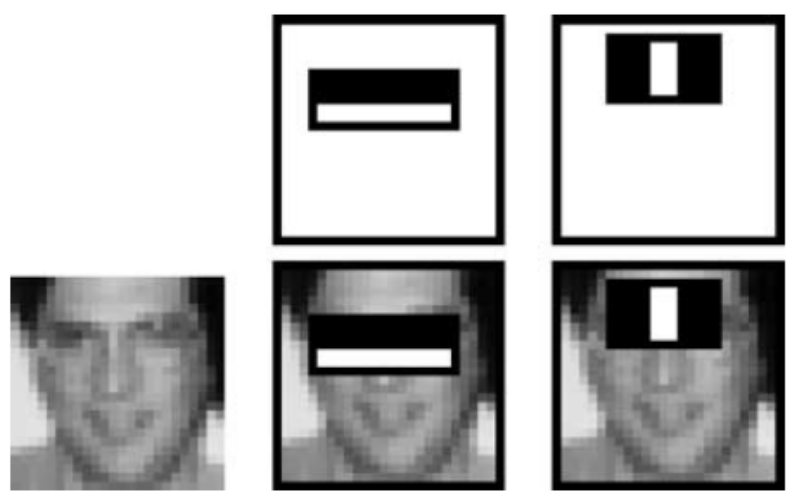

Figura 3.3: Aplicando as características na imagem (extraída do artigo de Viola e Jones (2002)).

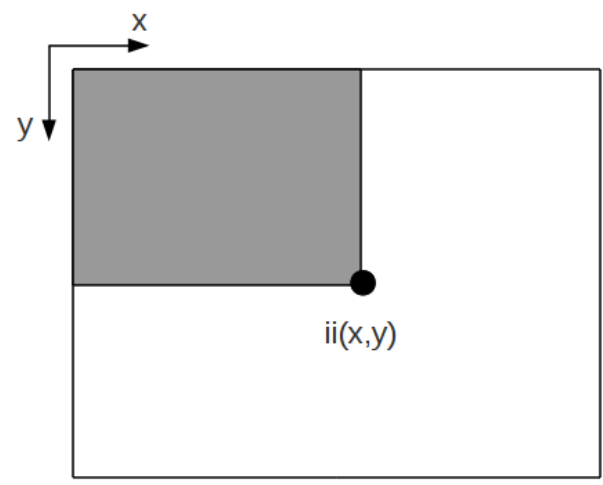

Figura 3.4: $O$ valor da imagem integral em $(x, y)$ é a soma dos pixels acima e à esquerda, de maneira inclusiva.

A motivação para o cálculo das características com o uso da imagem integral é que seu custo computacional é baixo, exigindo poucos acessos à memória (no máximo nove) e com o mínimo necessário de operações aritméticas de soma e subtração. Para maior clareza, considere a figura 3.5, onde se deseja calcular o valor da soma dentro da área $\mathrm{D}$, que pode ser obtido pela operação $4+1-(2+3)$.

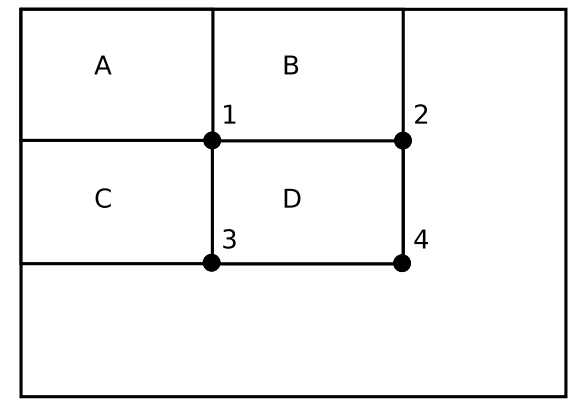

Figura 3.5: Cálculo da característica. Imagem adaptada de Viola e Jones (2002) . 


\subsubsection{Algoritmo de AdaBoost}

AdaBoost, abreviação de Adaptive Boosting, é uma técnica de aprendizado de máquina para a seleção de um conjunto de classificadores fracos, proposta por Freund e Schapire (1997). Em termos gerais, um classificador fraco é uma regra de decisão para classificar um exemplo de positivo ou negativo. Para se obter um classificador forte, uma combinação linear ponderada desses classificadores fracos é realizada, para um aumento no desempenho da detecção. Esse processo é chamado de boosting, cujos resultados serão utilizados para a formação de uma cascata de classificadores, que são estágios de classificadores fortes, a ser detalhado nas subseções 3.2.2 e 3.2.3.

Em uma subjanela simples de tamanho 24x24, por exemplo, existem mais de 160 mil características. Computar os valores de todas essas características na detecção é muito dispendioso computacionalmente. A seleção de alguns classificadores desse conjunto de características e sua posterior combinação pode criar um classificador robusto, que é a ideia central do algoritmo de AdaBoost.

Dado um conjunto de classificadores fracos e um conjunto de dados de treinamento com imagens positivas (com a característica a ser detectada) e negativas (que não possui a característica), o uso do AdaBoost seleciona um conjunto de classificadores fracos e a função de classificação. A combinação desses classificadores fracos originando um classificador forte é chamado de boosting.

O treinamento do classificador como mostrado por Viola e Jones (2002) se procede da seguinte maneira:

1. As imagens de treinamento são dadas por $\left(x_{1}, y_{1}\right),\left(x_{2}, y_{2}\right), \ldots,\left(x_{n}, y_{n}\right)$, onde $y_{i}=[0,1]$ indica imagem negativa e positiva, respectivamente.

2. Os pesos são iniciados $w_{1, i}=\frac{1}{2 m}, \frac{1}{2 l}$ para $y_{i}=[0,1]$ respectivamente, onde $m$ e $l$ são os números de amostras negativas e positivas, respectivamente.

3. Para $t=1,2, \ldots, T$ :

- Normalizar os pesos $w_{t, i} \leftarrow \frac{w_{t, i}}{\sum_{j=1}^{n} w_{t, j}}$

- Selecionar o melhor classificador com relação ao erro do peso $\epsilon_{t}=\min _{f, p, \Theta} \sum_{i} w_{i} \mid h\left(x_{i}, f, p, \Theta\right)-$ $y_{i}$.

- Definir $h_{t}(x)=h\left(x, f_{t}, p_{t}, \Theta_{t}\right)$ onde $f_{t}, p_{t}$ e $\left.\Theta_{t}\right)$ são minimizadores de $\epsilon_{t}$

- Atualizar os pesos: $w_{t+1, i}=w_{t, i} \beta_{t}^{1-\epsilon_{i}}$ onde $\epsilon_{i}=0$ se o exemplo $x_{i}$ é classificado corretamente e $\epsilon_{i}=1$ caso contrário, e $\beta=\frac{\epsilon_{t}}{1-\epsilon_{t}}$

4. O classificador forte final é dado por $f(x)=\left\{\begin{array}{ll}1 & \sum_{t=1}^{T} \alpha_{t} h_{t}(x) \geq \frac{1}{2} \sum_{t=1}^{T} \alpha \\ 0 & \text { caso contrário }\end{array} \quad\right.$ onde $\alpha_{t}=$ $\log \frac{1}{\beta_{t}}$.

Em resumo, são fornecidas imagens que contém apenas os lábios (rotuladas com $y=1$ ) e imagens que não os contém (rotuladas com $y=0$ ), chamadas de imagens de treinamento positivas e negativas, respectivamente. O peso inicial das imagens de treinamento fornecidas é calculado $\left(w_{t, i}\right)$, e inicia-se o processo de boosting, onde em cada iteração $(t)$ normalizam-se os pesos e para cada característica, um limiar é calculado. O resultado é um classificador fraco, onde para cada 
um, o erro de classificação nos exemplos de treinamento é calculado pela soma ponderada. Entre as muitas características possíveis, o classificador com o erro mínimo é avaliado e selecionado para aquela rodada de boosting.

Na próxima rodada, os pesos são atualizados de modo que aumentam-se os pesos dos exemplos classificados incorretamente pelo classificador anterior e diminuem-se os pesos dos exemplos classificados corretamente. Deste modo, na próxima iteração o classificador dará maior ênfase aos exemplos classificados incorretamente. Os classificadores de cada iteração serão diferentes.

O classificador forte final é criado pela combinação dos classificadores fracos gerados e pelo ajuste do limiar que é a metade do peso dado aos classificadores.

\subsubsection{Cascata de classificadores}

O método AdaBoost permite criar um bom detector com o uso de muitas características, com uma taxa de deteç̧ão alta. Mas o uso de apenas um detector tem baixa velocidade de deteç̧ão, pelo fato de que deve-se calcular os valores de características para todas as subjanelas da imagem. Para um incremento no desempenho, vários estágios de classificadores são criados, para eliminar já nos estágios iniciais as subjanelas que não correspondam à característica procurada, diminuindo assim o número de subjanelas para verificação pelos estágios posteriores dos classificadores. Essa etapa é necessária pois o número de subjanelas que não têm a característica procurada é muito maior que o número de subjanelas que podem ter a característica procurada. Assim, o custo computacional é reduzido e a velocidade de detecção é aumentada. Esse conjunto de estágios de classificadores é chamado de cascata de classificadores, o que explica a adoção do termo cascata. A figura 3.6 mostra um esquema geral de funcionamento de uma cascata de classificadores. Cada estágio, que é um classificador forte, é treinado pelo AdaBoost, e a entrada inicial é uma subjanela. Caso não tenha a característica procurada, a subjanela é rejeitada por um processamento simples de algumas características. O tempo de computação aumenta conforme o estágio avança, pois as subjanelas aumentam em complexidade. Conforme as subjanelas passam pelos estágios, a maioria é rejeitada, e as restantes, após passarem pelo último estágio, são consideradas detecções.

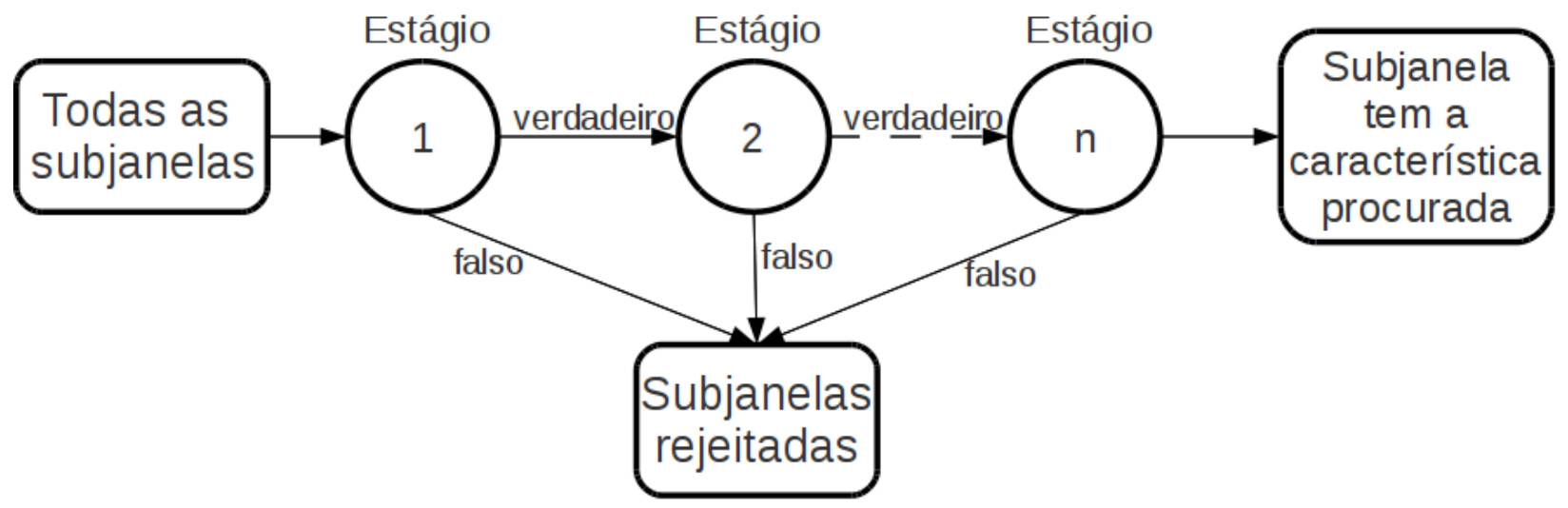

Figura 3.6: Cascata de classificadores. 


\subsection{Geração dos conjuntos de treinamento}

Para se obter o conjunto adequado de classificadores, o algoritmo de Viola-Jones requer uma etapa de treinamento. É necessário um conjunto de imagens chamadas de positivas, que contêm o objeto de interesse a ser detectado, nesse caso, os lábios. Em conjunto com essas imagens, é necessário ter as coordenadas da ROI dos lábios. O treinamento também recebe outro conjunto de imagens, chamadas de negativas, que não contêm o objeto de interesse. Usualmente são planos de fundo.

Um aspecto negativo da etapa de treinamento é a necessidade de rotular cada imagem, definindo manualmente uma ROI em torno da característica de interesse. O grande número de imagens positivas a serem rotuladas manualmente demanda muito tempo. Portanto, com essas considerações, optou-se por gerar e utilizar imagens sintéticas que são rotuladas automaticamente. Essa abordagem tem o potencial de uma geração controlada e automática de conjuntos de treinamento de tamanho arbitrariamente grande.

O trabalho de Mattos et al. (2010) foi adotado para gerar as imagens sintéticas, que são os dados positivos da etapa de treinamento. O trabalho apresenta um sistema de animação facial que usa modelos tridimensionais reais de pessoas, adquiridos por um scanner 3D. Para evitar a computação densa de correspondências, um conjunto esparso de pontos correspondentes é selecionado por emparelhamento estrutural de grafos, tendo como entrada uma face 3D com marcos já selecionados previamente. O registro é feito através da subdivisão da malha a partir do conjunto de marcos e os modelos são animados por duas técnicas: por interpolação e por modelo paramétrico. Mais detalhes dos processos de animação e seus princípios podem ser vistos em Mattos et al. (2010).

A vantagem de usar esses resultados é que as coordenadas da ROI dos lábios são obtidas automaticamente, além de ser possível especificar o ângulo de rotação desejado em um ou mais eixos, dos três disponíveis, em que as faces são animadas. A figura 3.8 mostra as configurações possíveis de rotação do modelo. Além disso, pode-se gerar conjuntos de treinamento anotados e condições controladas, o que fornece grande poder à abordagem.

O objetivo é a detecção em posições diferentes da frontal, e no estágio atual, são gerados dois conjuntos de treinamento. Para efeitos de identificação, são denominados $\mathrm{S}_{s 1}$ e $\mathrm{S}_{s 2}$. O primeiro conjunto, $\mathrm{S}_{s 1}$, simula a posição em que a câmera do celular está apontada para a face do usuário em um ângulo aproximado de 30 graus abaixo da linha de visão do usuário, como mostrado na figura 3.7. Isso simula uma situação de uso com o dispositivo móvel na mesa. A rotação mencionada corresponde a uma rotação de 30 graus no plano XZ no sentido horário. A visualização dos planos de rotação é mostrada na 3.8. Para o segundo conjunto de treinamento, $\mathrm{S}_{s 2}$, o modelo é rotacionado de 30 graus no sentido horário no plano XY e rotacionado de 45 graus no plano XZ, no sentido horário.

Num estágio futuro, pode-se realizar o treinamento de classificadores adicionais para outras posições não usuais. Uma limitação atual do uso das imagens sintéticas é a cor do interior da boca, que pode gerar classificadores que induzem a falsos positivos ou falsos negativos na etapa de detecção.

O código-fonte para as animações do trabalho de Mattos et al. (2010) foi disponibilizado para uso nesse trabalho de mestrado. Estão disponíveis 36 modelos de animação facial e arquivos de marcadores de pontos específicos da face, como pontos ao redor dos olhos, nariz e boca. Foram usadas apenas informações de textura e usou-se os pontos definidos no contorno interior da boca. 


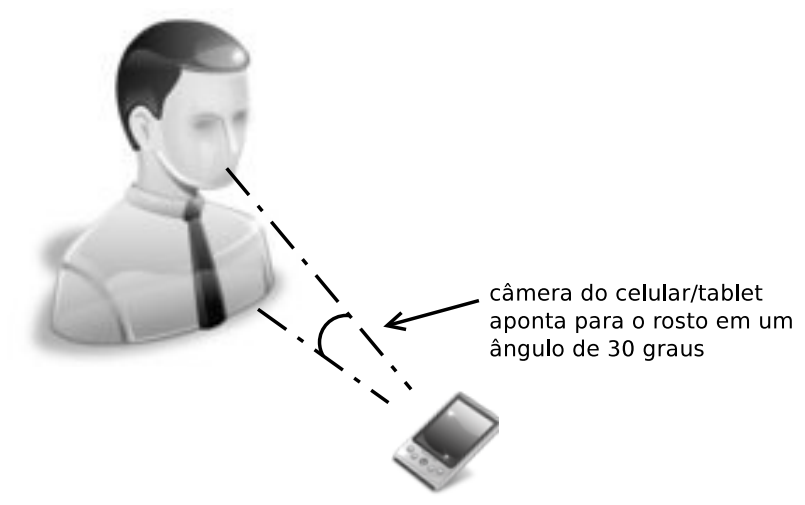

Figura 3.7: Configuração de uso.

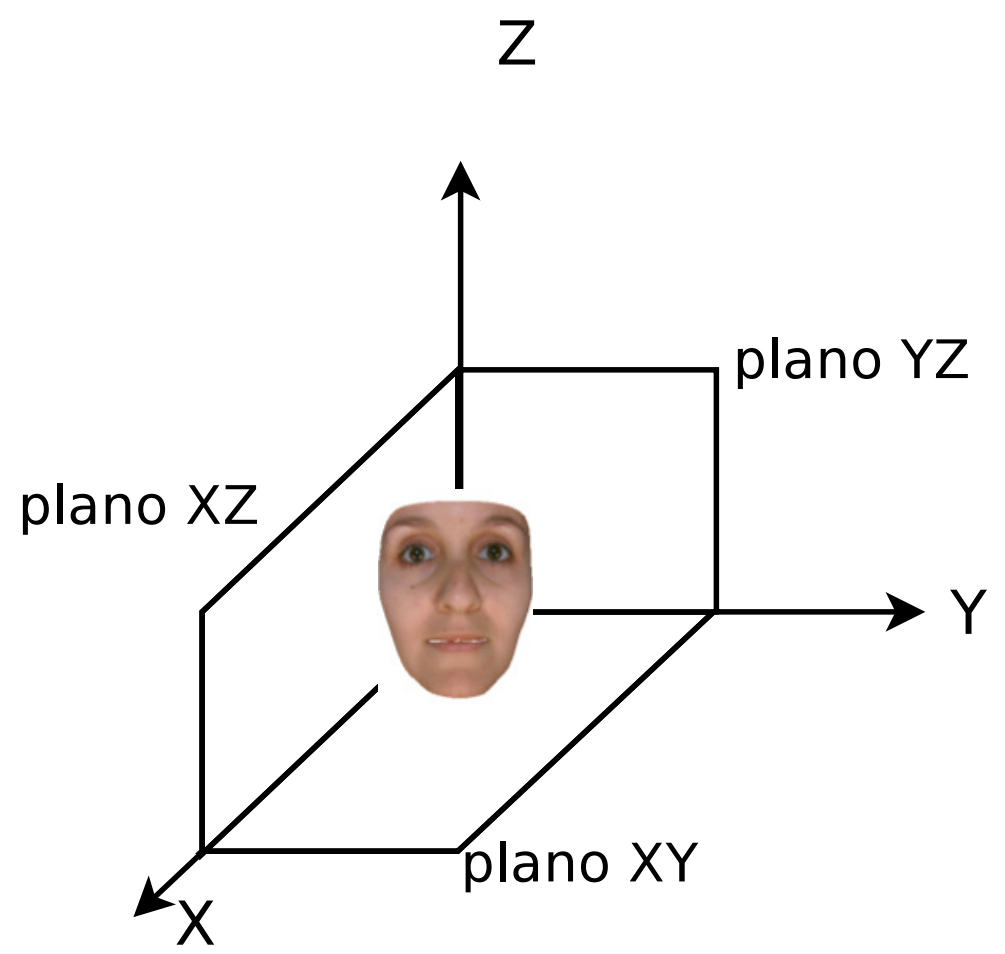

Figura 3.8: Planos de rotação do modelo.

A figura 3.9 mostra os pontos disponíveis, que estão na parte interior dos lábios. Como é necessária uma ROI que englobe os contornos externos dos lábios, foi adicionado um offset de 15 a 25 pixels nos pontos de interesse, dependendo do modelo. $\mathrm{O}$ código gerou quadros das animações de 36 modelos de faces reais e arquivos de saída indicando a ROI em volta dos lábios em cada quadro, gerando assim os groundtruths de cada modelo.

Para o primeiro conjunto de treinamento $\mathrm{S}_{s 1}$, com apenas uma rotação em um plano, foram geradas 2844 imagens. A figura 3.10 mostra os quatro primeiros modelos. Para o segundo conjunto $\mathrm{S}_{s 2}$, com rotações em dois planos, foram geradas 2880 imagens. A figura 3.11 mostra os quatro primeiros modelos. Ambos os conjuntos foram gerados a partir de 36 modelos de animação facial, com diversas expressões faciais.

Para as imagens negativas, foram usadas 3022 imagens de Seo (2008) e 23 imagens de autoria própria, totalizando 3045 imagens. Exemplos são mostrados nas figuras 3.12 e 3.13 .

Tanto as imagens positivas como as negativas são convertidas para escala de tons de cinza, pois 


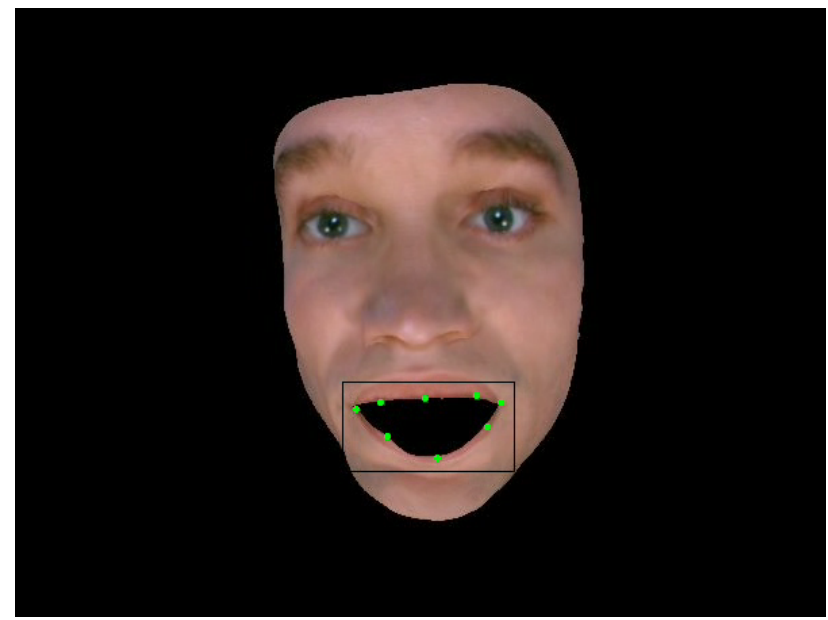

Figura 3.9: Pontos disponíveis da boca no modelo.

o treinamento não utiliza a informação de cor, apenas a informação de padrões na imagem, como a diferença entre regiões escuras e claras, como detalhado na subseção 3.2.1.
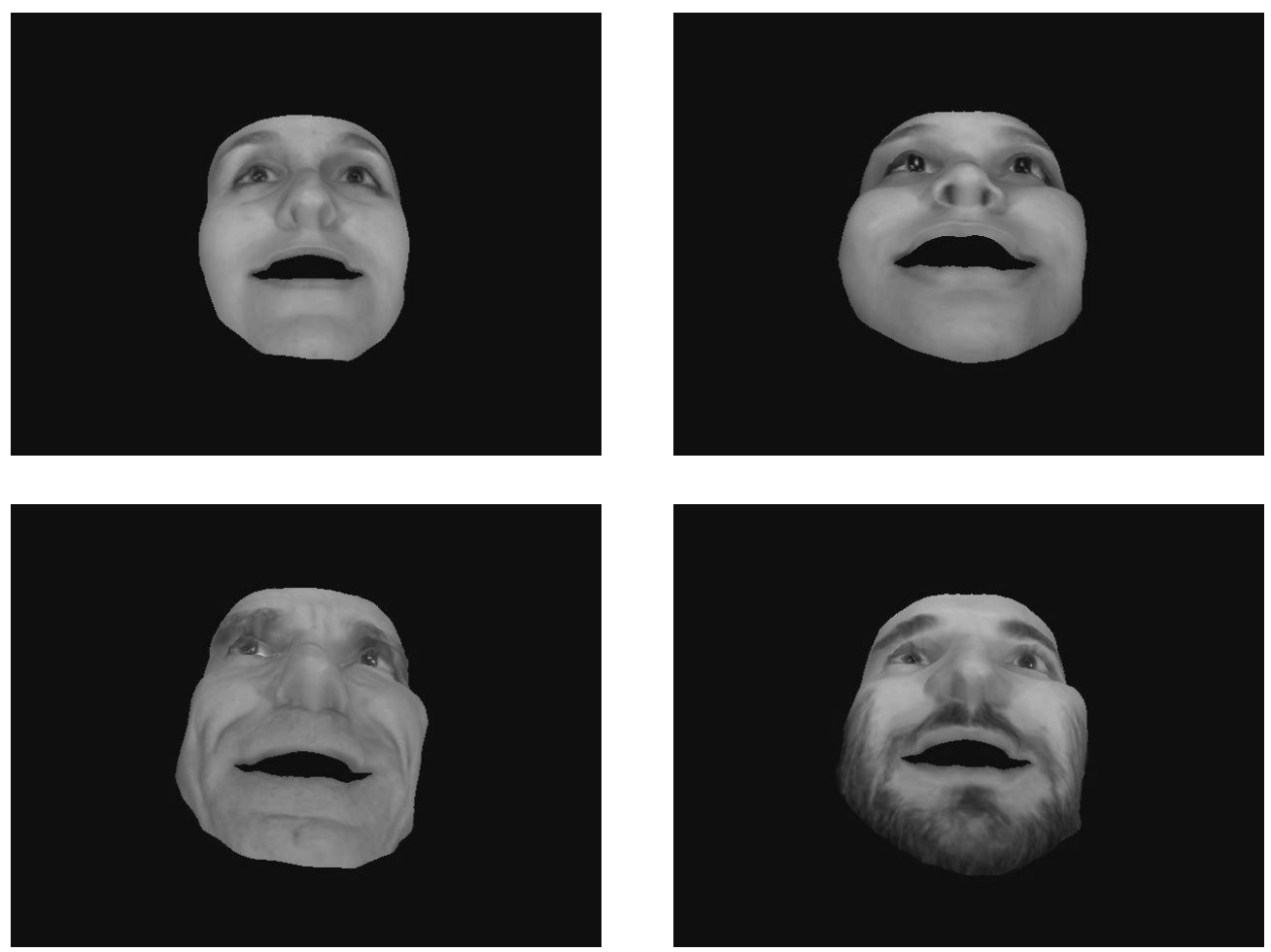

Figura 3.10: Exemplos do primeiro conjunto de imagens sintéticas, mostrando os quatro primeiros modelos.

A biblioteca OpenCV fornece as ferramentas necessárias para o treinamento e na pasta de executáveis da biblioteca, foram usados os programas binários opencv_createsamples e opencv_traincascade para o treinamento. O programa opencv_createsamples prepara os quadros de animações sintéticas gerados pelo programa de animação para o treinamento e usa como entrada os gabaritos dos modelos, que são arquivos em formato texto que contém as coordenadas da ROI dos lábios em cada quadro. O resultado, um arquivo no formato .vec, é usado no programa opencv_traincascade, que implementa os passos do algoritmo de aprendizado, o AdaBoost (subseção 3.2.2) e a estrutura de cascata (subseção 3.2.3). O resultado é um arquivo .xml, que representa o detector. 

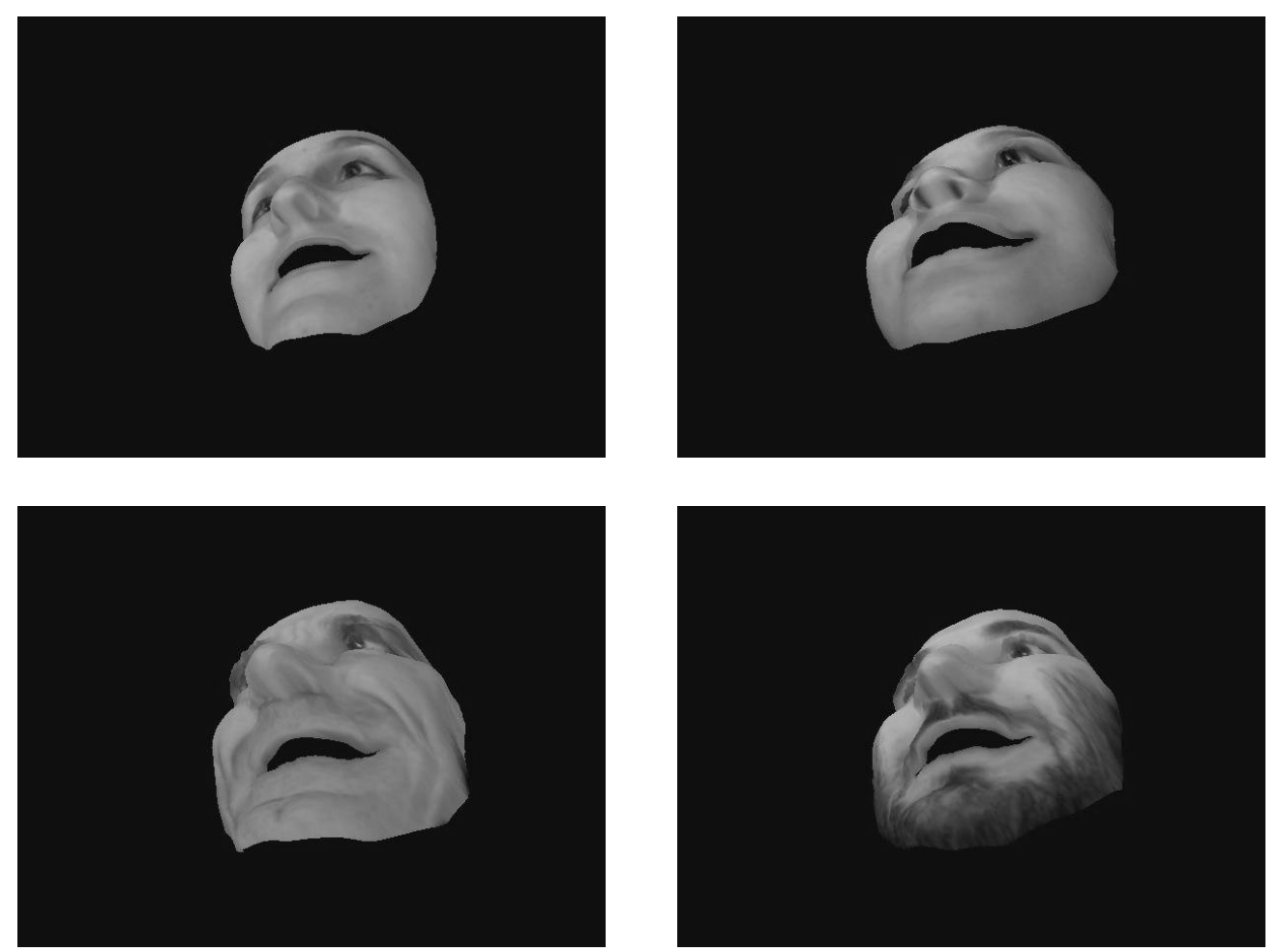

Figura 3.11: Exemplos do segundo conjunto de imagens sintéticas, mostrando os quatro primeiros modelos.

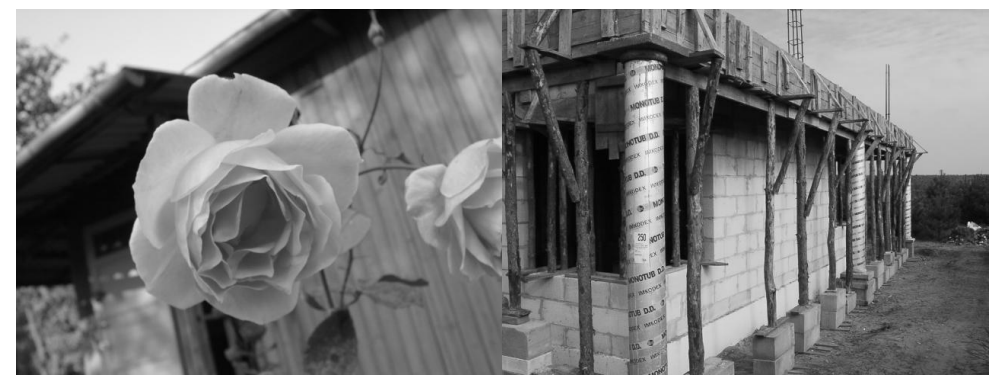

Figura 3.12: Exemplos de imagens negativas de Seo (2008).
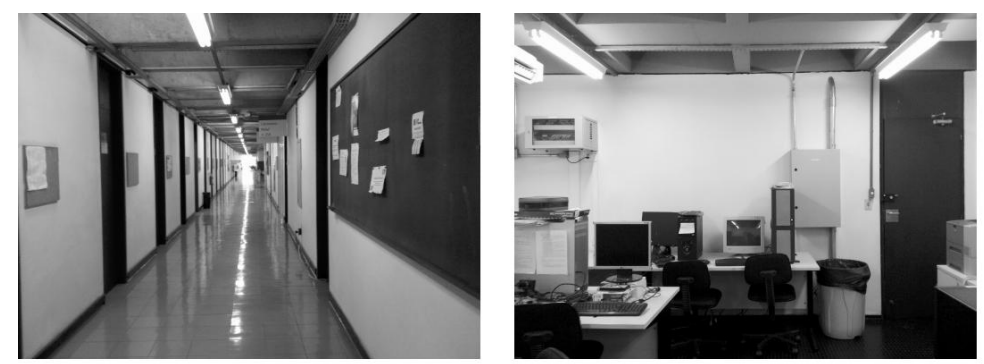

Figura 3.13: Exemplos de imagens negativas de autoria própria.

\subsection{Rastreamento}

Rastreamento é o processo de estimar o estado futuro de objetos ou pessoas (ou partes específicas) no espaço, a partir de informações de observações anteriores. Nesse projeto de mestrado, é feito o rastreamento da região ao redor da boca. O rastreamento foi adotado pelo fato de que o uso apenas de deteç̧ões consecutivas se mostrar inviável computacionalmente e ser sujeito a perdas das regiões de interesse. A detecção adotada neste projeto utiliza apenas informações de imagens 
em tons de cinza, enquanto que o rastreamento utiliza a informação de cor neste contexto.

Um dos algoritmos disponíveis e que utilizam informações de cores é o Camshift (do inglês, Continuously Adaptive Mean Shift) de Bradski (1998), que é adaptado do algoritmo Mean-Shift, de Cheng (1995). O mean-shift trabalha apenas com distribuições estáticas de probabilidade, sendo incapaz de lidar com distribuições dinâmicas. Camshift visa justamente trabalhar com essas distribuições dinâmicas, além de lidar com mudanças na escala, reajustando automaticamente o tamanho da janela de busca para o próximo quadro, se baseando nos cálculos de momentos da distribuição atual.

\subsubsection{Mean-shift}

O algoritmo Mean-Shift é um estimador de densidade de gradiente não-paramétrico, que segue na direção do máximo do gradiente da distribuição de probabilidade. Para efeitos de clareza, um passo do algoritmo é ilustrado na figura 3.14. Dada a posição inicial da moda (centro do círculo azul), a média ponderada dos pontos dentro da região de interesse (círculo azul) é computada e se torna a nova moda (o centro preto) do círculo, deslocando o círculo. Esse processo é repetido até o critério de convergência ser atingido, ou seja, quando o centro do círculo não se deslocar mais ou atingir o número máximo de iterações.

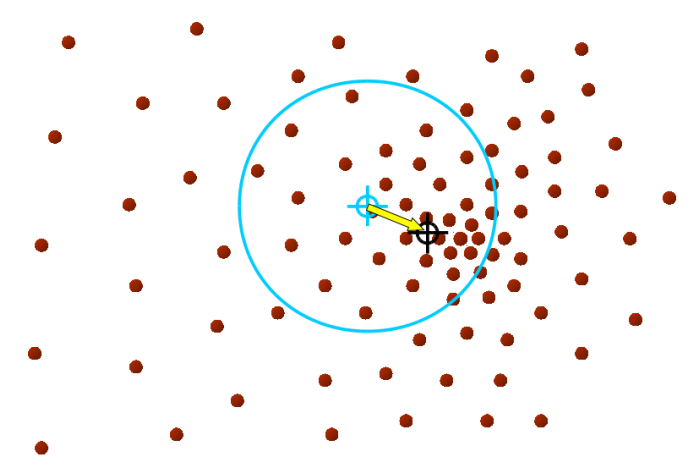

Figura 3.14: Um passo do mean-shift (figura adaptada de notas de aula de Ukrainitz e Sarel (2004)).

Para o cálculo do centroide, são calculados os momentos da imagem de ordem zero (equação 3.2) e um (equação 3.3):

$$
\begin{gathered}
M_{00}=\sum_{x} \sum_{y} P(x, y) \\
M_{10}=\sum_{x} \sum_{y} x P(x, y), \quad M_{01}=\sum_{x} \sum_{y} y P(x, y)
\end{gathered}
$$

onde $P(x, y)=h(I(x, y))$ é a distribuição de probabilidade do histograma de retroprojeção na posição $(x, y)$ dentro da janela de busca $I(x, y)$, que é computado do histograma $h$ da imagem $I$. Com os momentos calculados, a posição média do objeto de interesse pode ser calculada por:

$$
x_{c}=\frac{M_{10}}{M_{00}} ; \quad y_{c}=\frac{M_{01}}{M_{00}}
$$

que atualizará a localização da janela de busca, para nova iteração do mean-shift até atingir convergência (quando o centro da janela já não muda ou atinge um critério de término).

Para obter a imagem de probabilidade é usado um método que atribui a cada pixel da imagem 
sua probabilidade de pertencer ao objeto-alvo. O método é chamado de retroprojeção do histograma, podendo ser aplicado ao canal matiz (hue) da imagem convertida no espaço de cores HSV. Em primeiro lugar, o histograma do objeto de interesse é calculado, na área de interesse definida manualmente ou por deteç̧ão, sendo chamado de histograma modelo. Realiza-se uma projeção do histograma modelo com o histograma da imagem em quadros consecutivos, resultando em uma imagem em que a intensidade de cada pixel é a probabilidade de que aquele pixel observado nos quadros consecutivos pertença ao histograma modelo.

\subsubsection{Camshift}

O algoritmo Camshift é derivado do mean-shift, com a diferença de ser capaz de lidar com distribuições dinâmicas de probabilidade e mudanças na escala e rotação do objeto rastreado. De outro modo, a janela de busca varia de tamanho, se adaptando com as distribuições dinâmicas, ao contrário do mean-shift, que usa sub-janela de tamanho fixo.

Os passos do algoritmo são os seguintes:

1. Localização inicial da janela de busca é definida (manualmente ou por métodos automáticos de detecção);

2. Calcula-se a distribuição de probabilidade para a janela de busca do mean-shift, por retroprojeção do histograma;

3. Calcula-se o mean-shift até atingir a convergência ou um critério de término de iteração. Nesse passo são calculados e armazenados o momento de ordem zero e coordenadas do centroide;

4. A janela de busca para o próximo quadro é centralizada no centro do centroide e a nova escala é calculada;

5. Volta ao passo 2 .

A informação da matiz é extraída a cada quadro, e definem-se valores mínimos e máximos de threshold, de forma empírica. Em seguida, é calculada a retroprojeção do histograma, que será passada para o mean-shift no passo 3.

Para se obter o fator de escala, é necessário calcular o momento de ordem dois (equação 3.5):

$$
M_{20}=\sum_{x} \sum_{y} x^{2} P(x, y), \quad M_{02}=\sum_{x} \sum_{y} y^{2} P(x, y)
$$

que é fornecido pela equação 3.6 :

$$
\text { razão }=\frac{M_{20}}{x_{c}^{2}} / \frac{M_{02}}{y_{c}^{2}}
$$

O tamanho da janela de busca é atualizado pela equação 3.7:

$$
\text { largura }=\sqrt{2 M_{00}} \cdot \text { razão } ; \quad \text { altura }=\sqrt{2 M_{00} / \text { razão }}
$$

e a janela é centralizada no centroide. Em seguida, inicia-se a computação do próximo quadro. 


\subsubsection{Modificações}

A versão original do Camshift não atende de forma satisfatória aos propósitos atuais. No original, o mean-shift, uma das etapas do Camshift, se dá usando apenas o histograma do hue, um dos canais do sistema de cores HSV, obtido dos canais RGB sem nenhum pré-processamento. Desse modo, é sujeito a ruídos e a mudanças na iluminação, e o contraste entre a pele do rosto e os lábios é baixo, perdendo facilmente a ROI rastreada, principalmente em movimentos rápidos.

Com essas limitações em mente, são feitas modificações nas etapas do algoritmo Camshift para refinar o contraste entre o rosto e os lábios. Inicialmente, realiza-se um pré-processamento no sistema de cores RGB antes de transformá-lo para o sistema de cores HSV. O pré-processamento visa a otimizar o rastreamento e reduzir influências globais dos efeitos de iluminação. Usa-se o conceito de normalização por intensidade máxima, descrito em detalhes na subseção 3.4 .4 e após esse processamento, o canal RGB normalizado na intensidade máxima é convertido para HSV e extrai-se o canal hue, com valores de limiares (mínimo e máximo) determinados empiricamente. O resultado é um histograma do modelo, que contém o objeto de interesse, a ser repassado para o algoritmo mean-shift.

Ainda usando o quadro RGB normalizado na intensidade máxima, é feita a transformada para o espaço YIQ (Thejaswi e Sengupta (2008)), que na versão original, realizava a conversão a partir do espaço RGB não-normalizado. Para acentuar o contraste do canal Q, usa-se uma adaptação do trabalho de Ooi et al. (2008) da seguinte forma:

$Q_{\text {quad }}(x, y)=Q^{2}(x, y)$

$Q_{\text {mod }}(x, y)=0,75 \cdot Q_{\text {quad }}(x, y)+0,25 \cdot \frac{1}{Y(x, y)}$

onde $(x, y)$ representa a coordenada do pixel na imagem. Assim, $Q_{m o d}$ é binarizado, com limiar de $35 \%$ do maior valor do canal Q. Por fim, realiza-se uma operação AND entre a máscara binarizada do canal $Q_{m o d}$ e o histograma de retroprojeção. O resultado dessa operação AND é repassado para o algoritmo mean-shift.

Para efeitos de clareza, a figura 3.17 mostra o algoritmo original e a figura 3.18 , o modificado. A figura 3.15 mostra as operações intermediárias feitas com a imagem de retroprojeção e a figura 3.16 mostra as operações realizadas no canal Q.
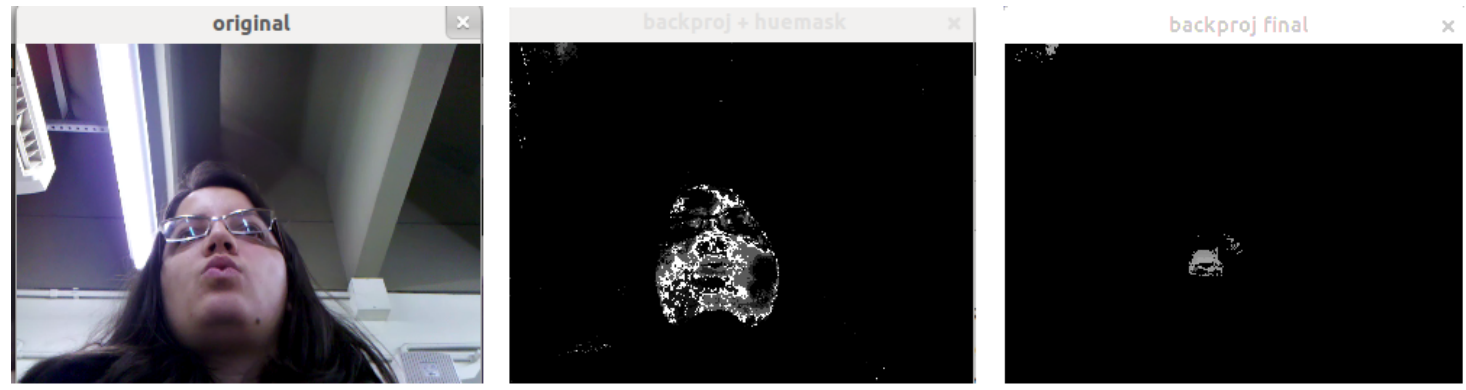

Figura 3.15: A imagem à esquerda mostra o quadro original. A imagem do centro mostra a imagem de retroprojeção original enquanto a imagem à direita mostra o resultado da operação AND entre o canal $Q$ modificado e a imagem de retroprojeção. Note que a região dos lábios recebeu um destaque maior nesse resultado. 


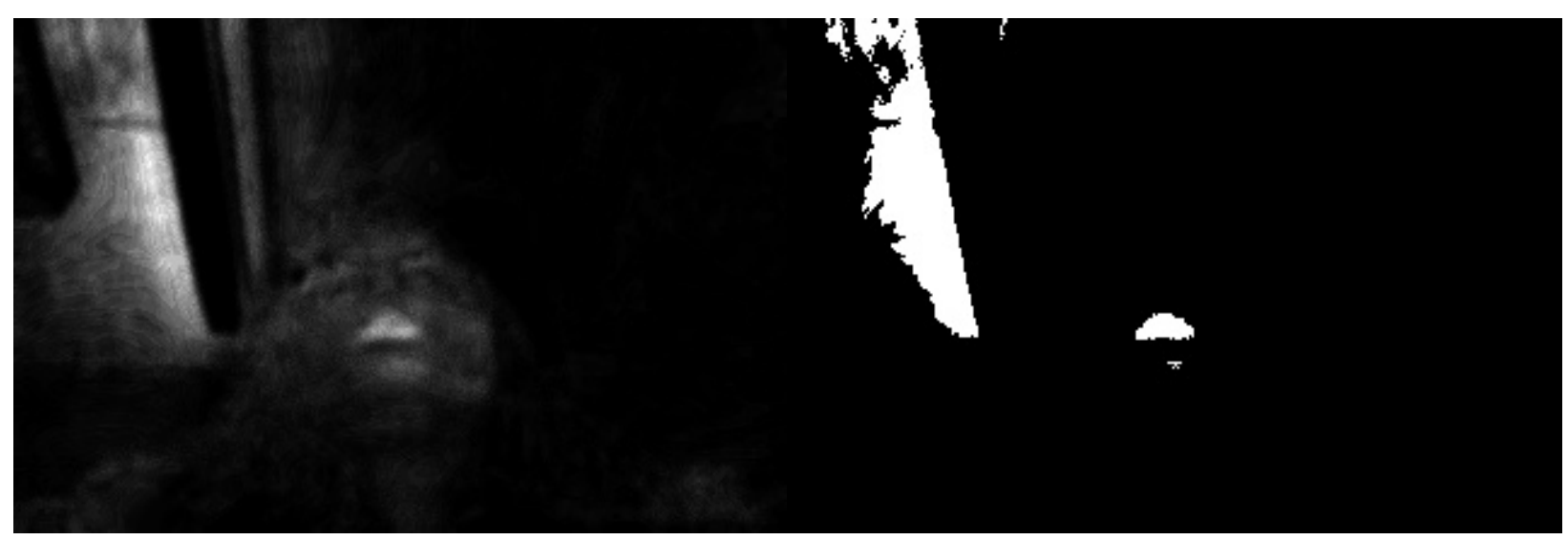

(a) Canal $Q$ modificado.

(b) Máscara do canal $Q$.

Figura 3.16: Operações realizadas no canal Q. A máscara binária é obtida por limiarização, com valor limite de $35 \%$ do maior valor do canal $Q$.

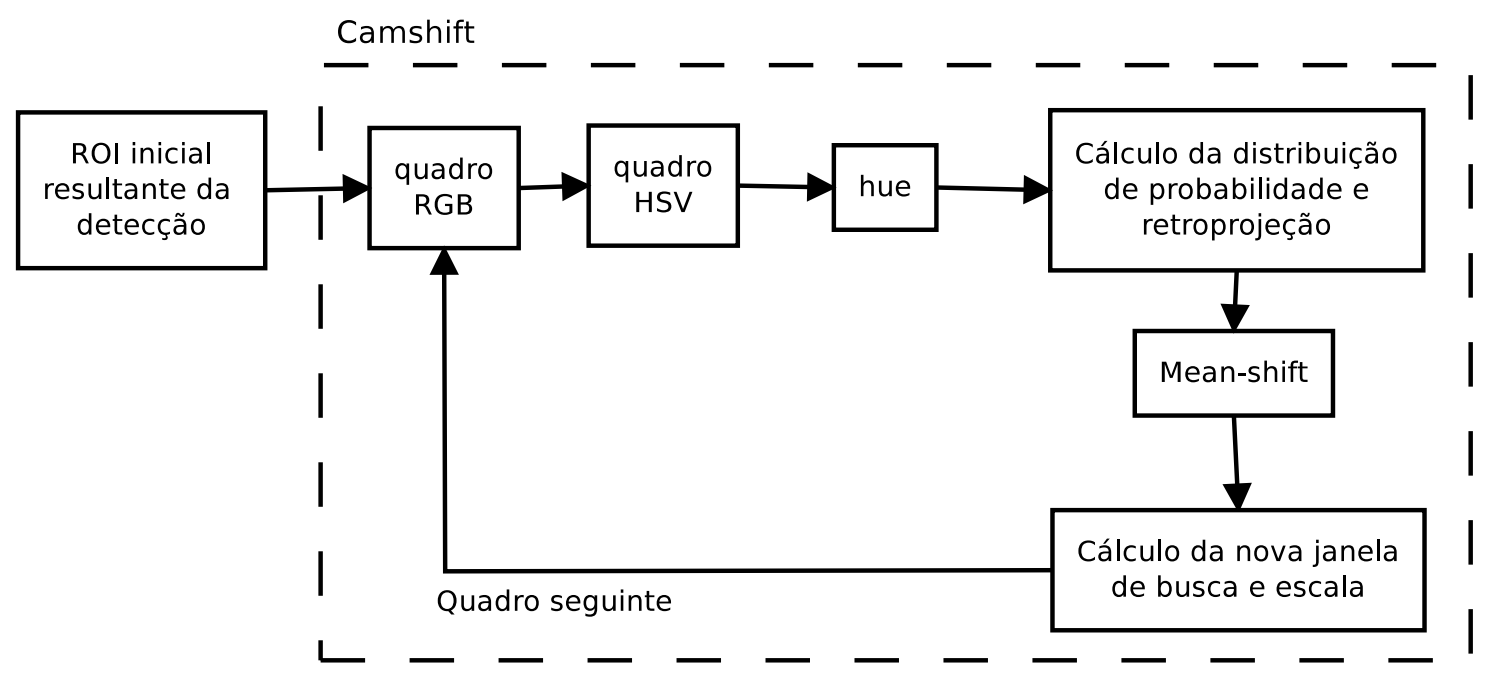

Figura 3.17: Algoritmo Camshift original.

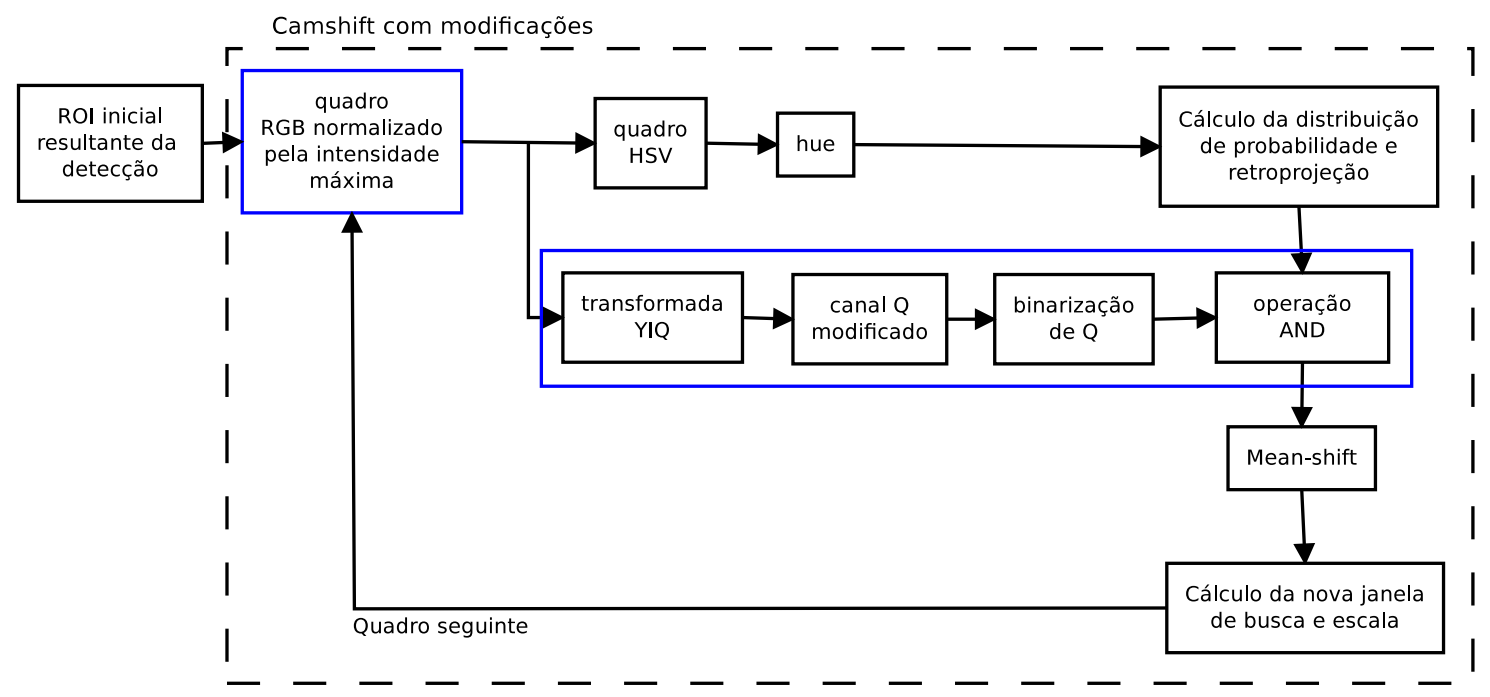

Figura 3.18: Algoritmo Camshift modificado. 


\subsubsection{Espaço de cores utilizados no rastreamento}

A segmentação de imagens pode ser obtida pelo uso de informações do espaço de cores RGB ou pela realização de transformadas para outros espaços de cores que enfatizem o contraste entre a região dos lábios e a face. São descritos os espaços de cores usados na etapa do rastreamento.

\section{Espaço de cor RGB}

O espaço RGB codifica informações de cores com a combinação de três cores: vermelho $(\mathrm{R})$, verde $(\mathrm{G})$ e azul (B). O espaço não separa a informação da crominância e iluminação. Usualmente os valores de cada canal variam de 0 a 255 .

Uma extensão é o espaço RGB normalizado, que normaliza cada vetor de pixel com relação à soma dos elementos do vetor (equação 3.8 ):

$$
\begin{aligned}
& r(x, y)=\frac{R(x, y)}{R+G+B} \\
& g(x, y)=\frac{G(x, y)}{R+G+B} \\
& b(x, y)=\frac{B(x, y)}{R+G+B}
\end{aligned}
$$

sendo que $r, g$ e $b$ são as cores normalizadas de R, G e B, respectivamente. A normalização diminui a dependência da iluminação na cromaticidade. Em Dargham e Chekima (2006), foi sugerido o conceito de normalização por intensidade máxima, para apresentar melhores resultados no contraste entre a região da pele e dos lábios. Para uma imagem com $m \mathrm{x} n$ pixels, os valores das componentes RGB normalizadas na intensidade máxima são obtidos por:

$$
\begin{aligned}
& r(x, y)=\frac{R(x, y)}{\operatorname{Max}(R+G+B)} \\
& g(x, y)=\frac{G(x, y)}{\operatorname{Max}(R+G+B)} \\
& b(x, y)=\frac{B(x, y)}{\operatorname{Max}(R+G+B)}
\end{aligned}
$$

onde $(x, y)$ representa a coordenada do pixel na imagem e $\operatorname{Max}(R+G+B)$ representa o maior valor obtido da soma de cada pixel nos três canais de cor considerando toda a imagem.

\section{Espaço de cor HSV}

O espaço de cor HSV é formado por três componentes, a matiz (do inglês, hue, H), a saturação (S) e o valor (V). É uma transformação não linear do espaço RGB. Considere o espaço RGB normalizado, onde cada uma das componentes varia de 0 a 1.0, sendo que $M A X$ e $M I N$ são, respectivamente, o valor máximo e mínimo desse espaço normalizado. Para obter as componentes $\mathrm{H}, \mathrm{S}$ e V, temos: 


$$
\begin{aligned}
& H= \begin{cases}60 \times \frac{G-B}{M A X-M I N}+0, & \text { se } M A X=R \\
60 \times \frac{G-B}{M A X-M I N}+360, & \text { se } M A X=R \\
& \text { e } G<B \\
60 \times \frac{B-R}{M A X-M I N}+120, & \text { se } M A X=G \\
60 \times \frac{R-G}{M A X-M I N}+240, & \text { se } M A X=B\end{cases} \\
& S=\frac{M A X-M I N}{M A X} \\
& V=M A X
\end{aligned}
$$

\section{Espaço de cor YIQ}

O espaço de cor YIQ é usado pelo sistema de cor de TV NTSC, onde a componente Y representa a luminosidade e a cromaticidade é representada pelos canais I e Q. Em Thejaswi e Sengupta (2008), o canal Q é usado para a detecção dos lábios, por delinear bem a diferença entre a pele e os lábios. A transformada YIQ é obtida do canal RGB da seguinte maneira:

$$
\left[\begin{array}{c}
Y \\
I \\
Q
\end{array}\right]=\left[\begin{array}{ccc}
0.299 & 0.587 & 0.114 \\
0.595716 & -0.274453 & -0.321263 \\
0.211456 & -0.522591 & 0.31135
\end{array}\right]\left[\begin{array}{c}
R \\
G \\
B
\end{array}\right]
$$




\section{Capítulo 4}

\section{Resultados experimentais}

O presente capítulo apresenta os resultados experimentais obtidos com o método proposto em diversas sequências de vídeo gravadas em um celular e em imagens sintéticas. Os parâmetros de avaliação usados são: o número de acertos, o número de falsos positivos e o número de falsos negativos, que são usados para calcular a precisão, a revocação e a acurácia. Na parte referente ao rastreamento, além dos parâmetros já mencionados, também se usa a taxa de quadros por segundo (fps - frames per second) para avaliação. Esse capítulo apresenta resultados usando, além dos métodos descritos nesta dissertação, um detector clássico implementado no OpenCV. Os detectores adotados são descritos na primeira seção do capítulo atual.

O capítulo está dividido em três seções. A primeira seção descreve a configuração usada para realizar os experimentos, descrevendo sua implementação, os dados dos testes e as métricas utilizadas para avaliar o desempenho. Na segunda seção são mostrados os resultados obtidos com o uso apenas de detecção, tanto nas sequências reais como nas sintéticas. A terceira seção mostra os resultados obtidos na detecção e no rastreamento.

\subsection{Configuração do experimento}

\subsubsection{Implementação}

A implementação foi realizada tanto em um laptop como em um dispositivo móvel. Para o laptop, a implementação foi feita na linguagem $\mathrm{C}++$ com o auxílio da biblioteca de visão computacional OpenCV, versão 2.4.2 ${ }^{1}$. Para o dispositivo móvel, a implementação foi feita na linguagem Java e também com o auxílio de uma versão do OpenCV (2.4.2) específica para o Android ${ }^{2}$. Foram usadas funções da biblioteca para o treinamento, deteç̧ão e rastreamento, aplicando as devidas modificações quando necessário. O dispositivo móvel utilizado é o celular Samsung Galaxy S II, modelo GT-I9100, processador dual-core Cortex A9 1,2GHz, 1GB de RAM e sistema operacional Android, versão 4.0.3 (Ice Cream Sandwich). Os testes de avaliação de desempenho foram feitos em um notebook Dell Inspiron 1545, com processador Intel Core 2 Duo 2,2 Ghz, 4GB de RAM e sistema operacional Ubuntu 12.04.

\footnotetext{
${ }^{1}$ Disponível no site http://opencv.willowgarage.com/wiki

${ }^{2}$ OpenCV4Android: http://opencv.org/platforms/android.html
} 


\subsubsection{Dados do treinamento e teste}

Os vídeos usados nos experimentos são obtidos através de diversos smartphones. São gravadas quatro sequências, descritas a seguir:

- Sequência $1\left(\mathrm{~S}_{r 1}\right)$ : duração de 12 segundos gravada no celular Motorola Milestone, com resolução $720 x 480$ pixels e 25 quadros por segundo.

- Sequência $2\left(\mathrm{~S}_{r 2}\right)$ : duração de 7 segundos gravada no celular Samsung Galaxy 5, com resolução $320 \times 240$ pixels e 25 quadros por segundo.

- Sequência $3\left(\mathrm{~S}_{r 3}\right)$ : duração de 14 segundos gravada no celular Nokia N97, com resolução $176 \times 144$ pixels e 30 quadros por segundo.

- Sequência $4\left(\mathrm{~S}_{r 4}\right)$ : duração de 8 segundos gravada no celular Samsung Galaxy S II, com resolução 488x314 pixels e 25 quadros por segundo.

As sequências de 1 a 3 são gravadas com um usuário em uma posição sem grandes desvios da posição frontal, com o celular apoiado na mesa. A sequência 4 é gravada com uma posição intermediária entre a frontal e a de perfil. A figura 4.1 mostra 5 quadros de cada sequência.
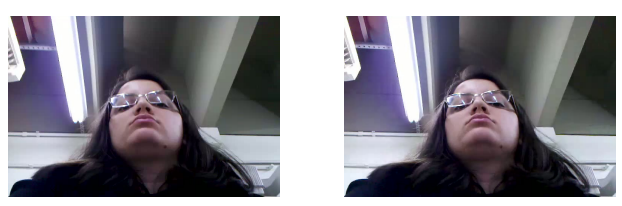

\section{Sequência 1}
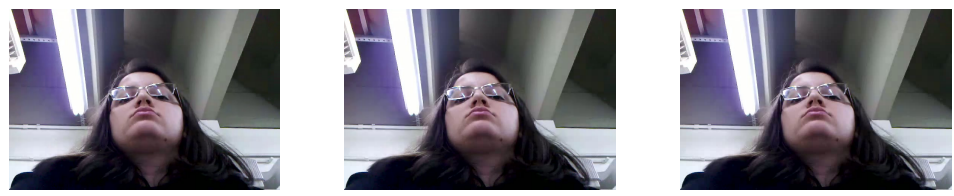

\section{Sequência 2}
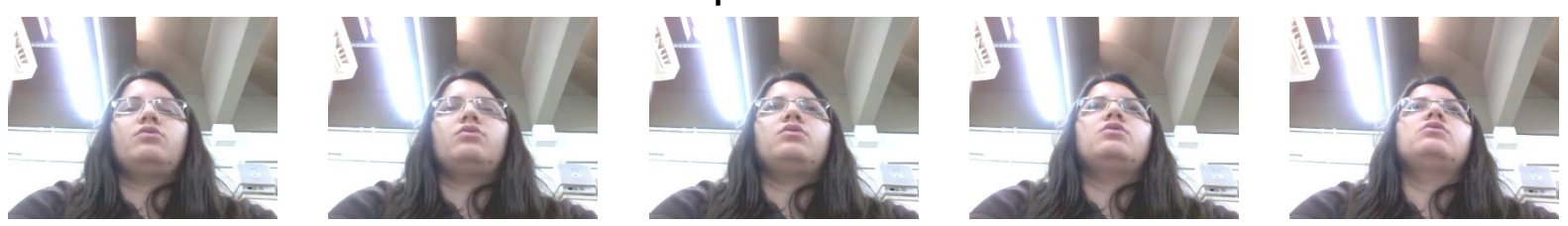

\section{Sequência 3}
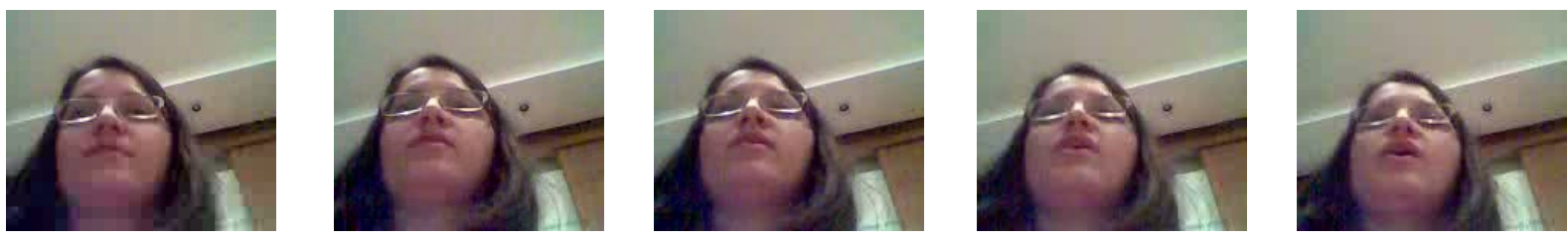

\section{Sequência 4}
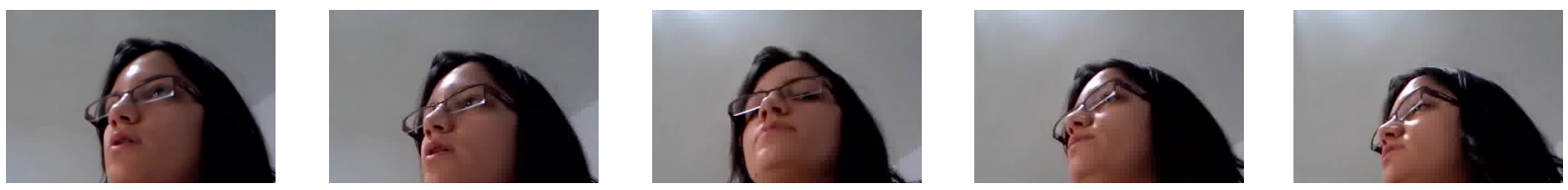

Figura 4.1: Amostra de 5 quadros das sequências usadas nos experimentos. 
Para os testes descritos na subseção 4.2.1, foram usados os mesmos dois conjuntos de imagens sintéticas do treinamento, mencionados na seção 3.3 , com 36 modelos. O primeiro conjunto $\left(\mathrm{S}_{s 1}\right)$ possui 2844 imagens e o segundo conjunto $\left(\mathrm{S}_{s 2}\right), 2880$ imagens, ambos com o groundtruth dessas imagens. A figura 4.2 mostra os 36 modelos usados nos testes.
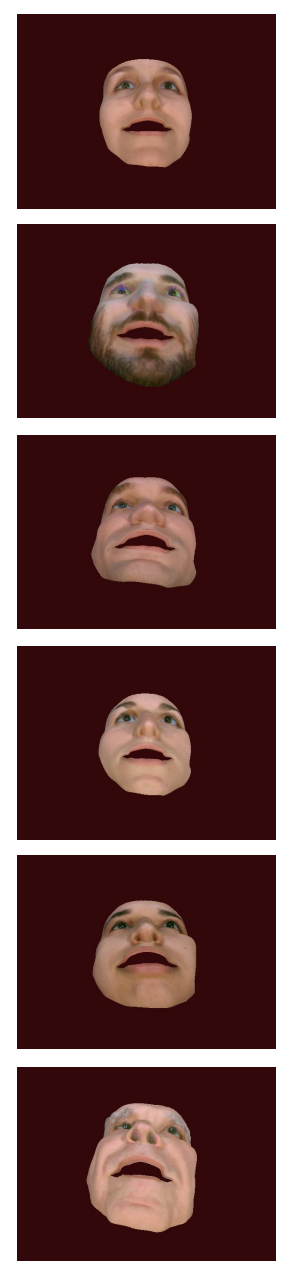
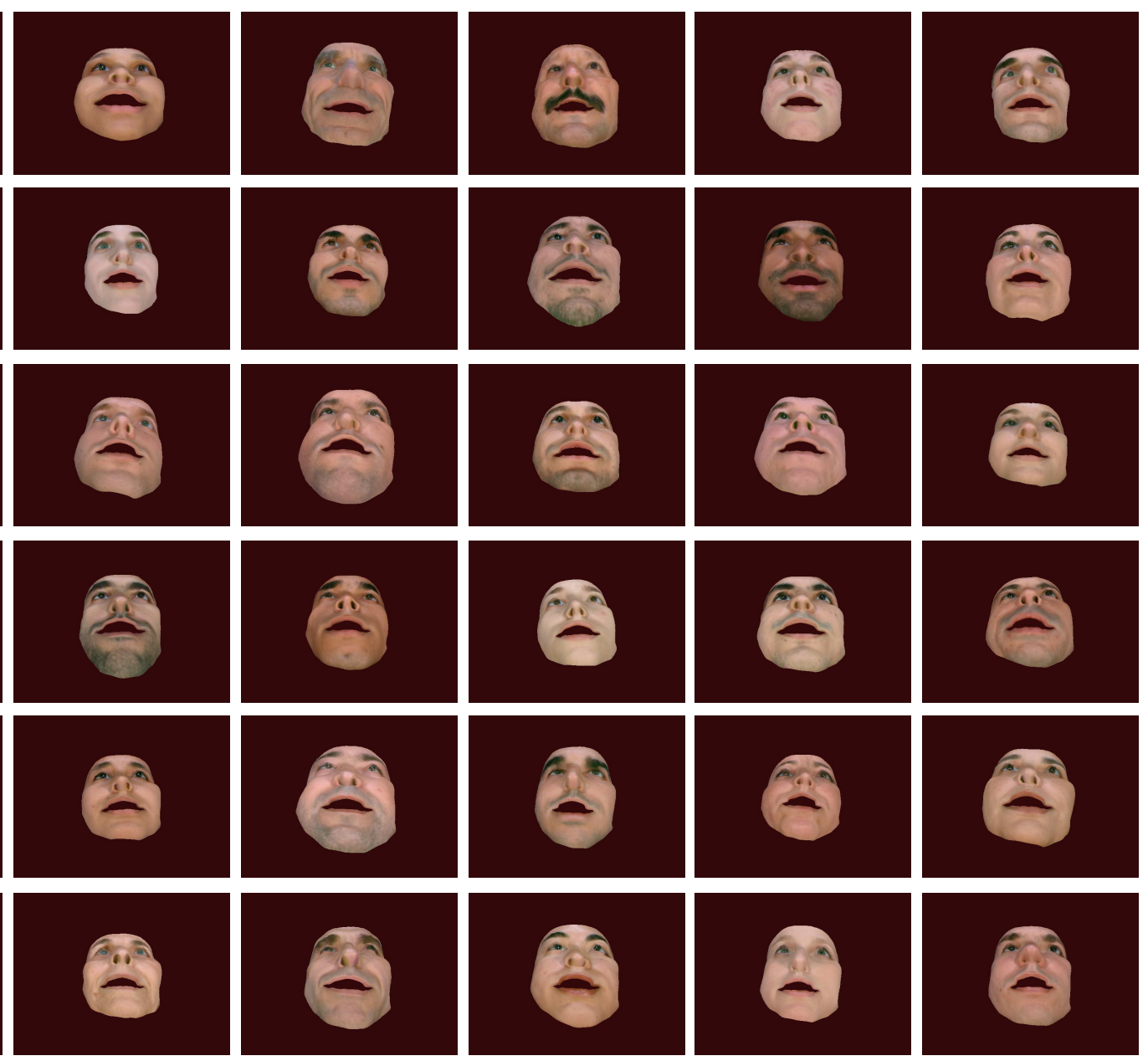

Figura 4.2: Os 36 modelos usados no treinamento e no teste.

São utilizados os seguintes detectores:

- D1 - detector que vem por padrão no OpenCV (Castrillón-Santana et al. (2008));

- D2 - detector treinado com imagens sintéticas com rotação de 30 graus no plano XZ no sentido horário (ver figura 4.3 para visualização dos planos);

- D3 - detector treinado com imagens sintéticas com rotação de 30 graus no sentido horário no plano XY e rotacionado de 45 graus no plano XZ, no sentido horário (ver figura 4.3 para visualização dos planos).

Não foi usada a resolução original em todos os vídeos, por não ser necessária uma resolução alta e para melhorar o desempenho. A resolução é diminuída para 320 pixels de largura e y de altura, sendo que y é calculado proporcionalmente em relação ao valor original, mostrado na equação 4.1. Esse cálculo é necessário para manter a proporção da altura. O cálculo não é necessário para a 


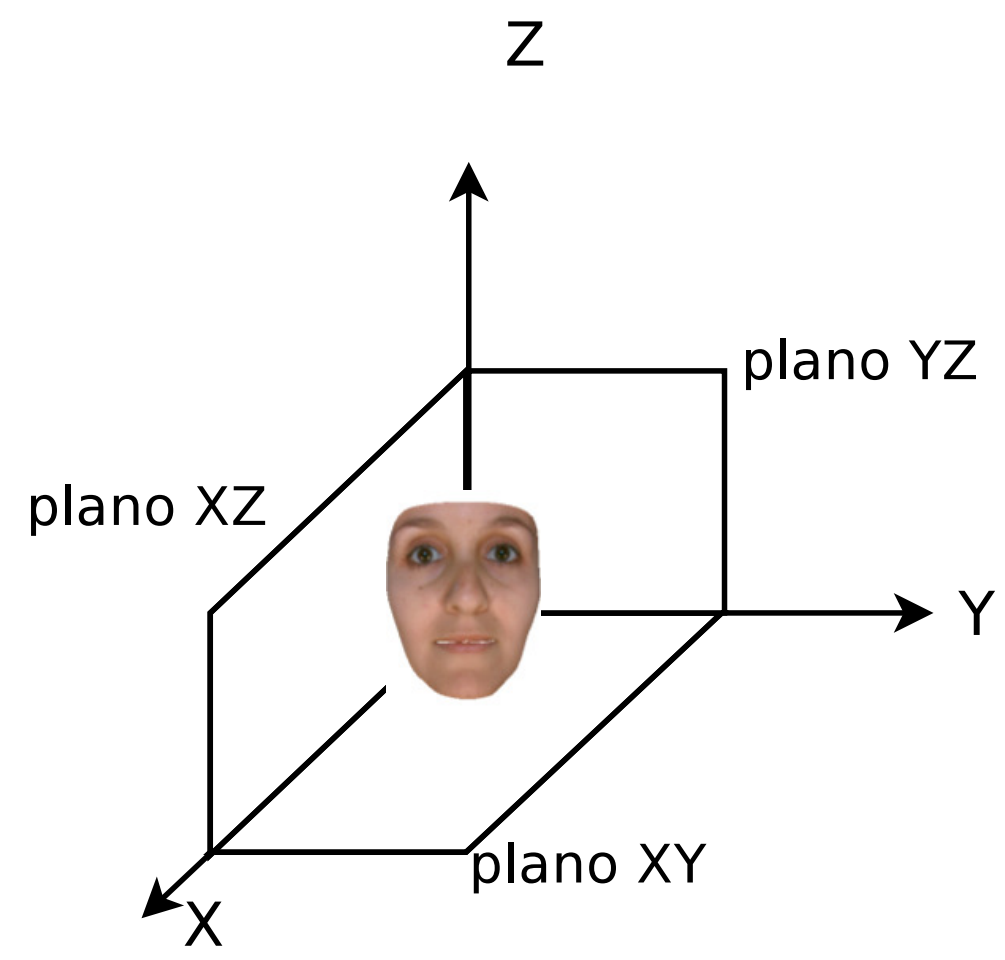

Figura 4.3: Planos de rotação do modelo.

sequência 3, por ter uma largura menor que 320 pixels.

$$
y=\frac{320 * h_{\text {original }}}{w_{\text {original }}}
$$

onde $h_{\text {original }}$ é a altura original da imagem e $w_{\text {original }}$ é a largura original da imagem. A redução da resolução diminui os custos computacionais.

\subsubsection{Métricas para avaliação dos resultados}

Um sistema de detecção pode cometer dois tipos de erros: falsos positivos e falsos negativos. Falsos positivos ocorrem quando há detecções em regiões que não contém a boca na imagem. Um falso negativo ocorre no caso em que a detecção falha em detectar a boca existente na imagem. Em conjunto com esses erros, usa-se o número de acertos para computar a precisão (equação 4.2), a revocação (equação 4.3) e a acurácia (equação 4.4).

$$
\begin{gathered}
\text { Precisão }=\frac{t p}{t p+f p} \\
\text { Revocação }=\frac{t p}{t p+f n} \\
\text { Acurácia }=\frac{t p+t n}{t p+t n+f p+f n}
\end{gathered}
$$

onde $t p$ representa o número de acertos, $f p$ o número de falsos positivos, $f n$ o número de falsos negativos e tn o número de negativos verdadeiros (onde o detector corretamente não faz nenhuma detecção na imagem que realmente não contém a boca). Para o cálculo da acurácia, como todos os 
quadros contêm a boca, o número de negativos verdadeiros é zero $(t n=0)$ nesse teste.

Para determinar se a ROI detectada corresponde ao groundtruth, é usada a métrica da interseção sobre união (IOU - intersection-over-union), também conhecida como coeficiente de Jaccard (Tan et al. (2005)), para medir a sobreposição de duas ROIs. Consiste na razão entre a área da interseção de duas ROIs e a área da união de duas ROIs:

$$
I O U=\frac{\text { Área }\left(r o i_{\text {ref }} \cap \text { roi } i_{\text {atual }}\right)}{\text { Área }\left(r o i_{\text {ref }} \cup r o i_{\text {atual }}\right)}
$$

onde roi $_{\text {ref }}$ representa a ROI do groundtruth e roi $i_{\text {atual }}$ representa a ROI da detecção ou rastreamento. A área da união é obtida por:

$$
\text { Área }\left(r o i_{r e f} \cup r o i_{a t u a l}\right)=\operatorname{Área}\left(r o i_{r e f}\right)+\operatorname{Área}\left(r o i_{a t u a l}\right)-\operatorname{Área}\left(r o i_{r e f} \cap r o i_{a t u a l}\right)
$$

É considerado acerto na detecção se o valor de IOU é maior que 0,4 e no rastreamento se o valor de IOU é maior que 0,3 .

Finalizando, a tabela 4.1 reúne os dados, detectores e as métricas usados nos experimentos e comparações desta dissertação.

\begin{tabular}{|r|l|}
\hline Detectores & $\begin{array}{l}\text { D1: detector de boca incluso na biblioteca do OpenCV, detalhado na subseção 4.1.2. } \\
\text { D2: detector treinado com imagens sintéticas com rotação de } 30 \text { graus no plano XZ } \\
\text { no sentido horário, detalhado na subseção } 4.1 .2 .\end{array}$ \\
& $\begin{aligned} \text { D3: detector treinado com imagens sintéticas com rotação de } 30 \text { graus no sentido } \\
\text { horário no plano XY e rotacionado de } 45 \text { graus no plano XZ, no sentido horário, } \\
\text { detalhado na subseção 4.1.2. }\end{aligned}$ \\
\hline Dados & $\begin{array}{l}\mathrm{S}_{s 1} \text { e } \mathrm{S}_{s 2}: \text { Sequências sintéticas, detalhadas na subseção } 4.1 .2 . \\
\mathrm{S}_{r 1}, \mathrm{~S}_{r 2}, \mathrm{~S}_{r 3} \text { e } \mathrm{S}_{r 4} \text { : Sequências reais, detalhadas na subseção } 4.1 .2 .\end{array}$ \\
\hline Métricas & $\begin{array}{l}\mathrm{TP}, \mathrm{FN}, \mathrm{FP}, \text { precisão, revocação e acurácia: métricas de avaliação, detalhadas na } \\
\text { subseção 4.1.3. } \\
\text { IOU - Interseção sobre união, métrica de avaliação de sobreposição de duas ROIs, } \\
\text { equação 4.5. }\end{array}$ \\
\hline
\end{tabular}

Tabela 4.1: Sumário da avaliação de desempenho.

\subsection{Resultados da Detecção}

\subsubsection{Resultados com $\mathrm{S}_{s 1}$ e $\mathrm{S}_{s 2}$}

Para a demonstração da viabilidade de utilização de geração automática de conjuntos de treinamento com imagens sintéticas, é necessária uma comparação com um detector já consolidado, nesse caso, o detector de boca que está incluso no OpenCV.

Será usada a função do OpenCV detectMultiScale, onde os seguintes parâmetros são usados:

- Fator de escala de 1.1. O fator de escala representa, em termos percentuais, o quanto é aumentado o tamanho de uma janela de processamento de características a cada varredura da imagem. Fator de 1.1 significa que a janela é aumentada de $10 \%$ a cada varredura da 
imagem. A busca do objeto na imagem inteira é facilitada quando o classificador é escalonado para encontrar o objeto, em vez de escalonar a imagem.

- Número de vizinhanças: 1. Detecções adjacentes, cujas ROIs podem se sobrepor. Então detecções com pelo menos uma ROI sobreposta são fundidas.

- Tamanho mínimo possível do objeto: largura de 25 pixels e altura de 15 pixels. Objetos com dimensões menores não serão detectados.

Os seguintes detectores são avaliados: D1, D2 e D3, detalhados na subseção 4.1.2. Os detectores D1 e D2 são testados no primeiro conjunto de treinamento $\left(\mathrm{S}_{s 1}\right)$ e os detectores D1 e D3 são testados no segundo conjunto de treinamento $\left(\mathrm{S}_{s 2}\right)$.

As tabelas 4.2 e 4.3 sumarizam os resultados obtidos.

\begin{tabular}{|l|l|l|l|l|l|l|}
\hline Detector & TP & FN & FP & Precisão & Revocação & Acurácia \\
\hline D1 & 2446 & 398 & 2213 & 0,53 & 0,86 & 0,48 \\
\hline D2 & 2479 & 365 & 69 & 0,97 & 0,87 & 0,85 \\
\hline
\end{tabular}

Tabela 4.2: Tabela com os valores de precisão, revocação e acurácia para os resultados com os detectores D1 e D2 no conjunto $S_{s 1}$.

\begin{tabular}{|l|l|l|l|l|l|l|}
\hline Detector & TP & FN & FP & Precisão & Revocação & Acurácia \\
\hline D1 & 871 & 2009 & 1514 & 0,31 & 0,26 & 0,17 \\
\hline D3 & 2599 & 281 & 1621 & 0,62 & 0,90 & 0,58 \\
\hline
\end{tabular}

Tabela 4.3: Tabela com os valores de precisão, revocação e acurácia para os resultados com os detectores D1 e D3 no conjunto $S_{s 2}$.

Os resultados mostram que o treinamento de um detector com o uso de conjuntos de imagens sintéticas é possível, além de superar o detector D1 nas imagens sintéticas nos parâmetros avaliados. A geração automática de conjuntos de treinamento também possibilita realizar testes automatizados, já que o arquivo com o groundtruth é gerado automaticamente. No link http://www.vision.ime.usp.br/ giseli/dissertacao/videos estão disponíveis os vídeos, tanto com os quadros originais dos dois conjuntos de treinamento como os quadros com as marcações de deteç̧ão de cada detector usado, respectivamente.

\subsubsection{Resultados com $\mathrm{S}_{r 1}, \mathrm{~S}_{r 2}, \mathrm{~S}_{r 3}$ e $\mathrm{S}_{r 4}$}

A seção atual avalia a possibilidade de uso da detecção em todos os quadros, sem utilizar informação prévia do quadro anterior, ou seja, sem o uso de rastreamento. São usados os detectores avaliados na subseção 4.2.1 em sequências gravadas com celular. A figura 4.4 mostra uma amostra de detecção em 5 quadros de cada sequência.

As tabelas 4.4, 4.5 e 4.6 sumarizam os resultados obtidos com os detectores D1 e D2 para as sequências $\mathrm{S}_{r 1}, \mathrm{~S}_{r 2}$ e $\mathrm{S}_{r 3}$. A tabela 4.7 mostra os resultados obtidos com os detectores D1 e D3 para a sequência $\mathrm{S}_{r 4}$. O detector D2 não é testado para essa sequência por ser treinado apenas com imagens sintéticas sem grandes desvios da frontal, ao contrário de D3 que foi treinado para lidar especificamente com rotações, como descrito na seção 3.3. 


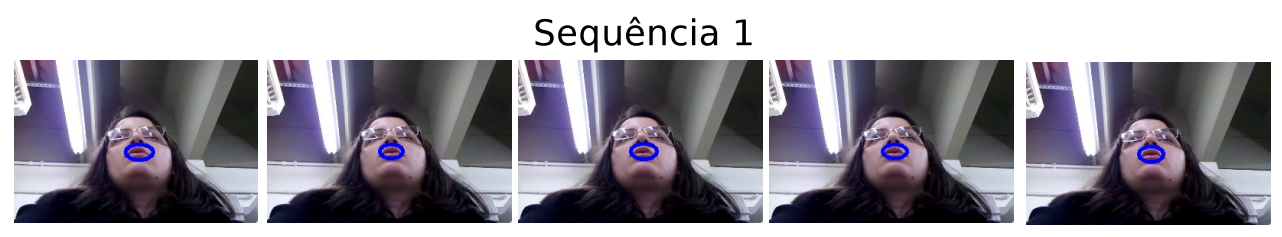

\section{Sequência 2}
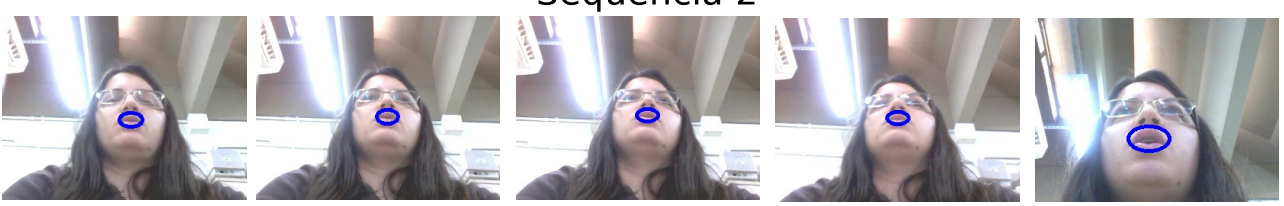

\section{Sequência 3}
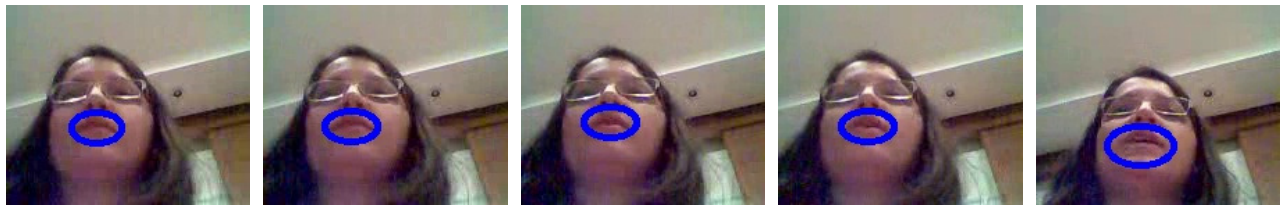

Sequência 4
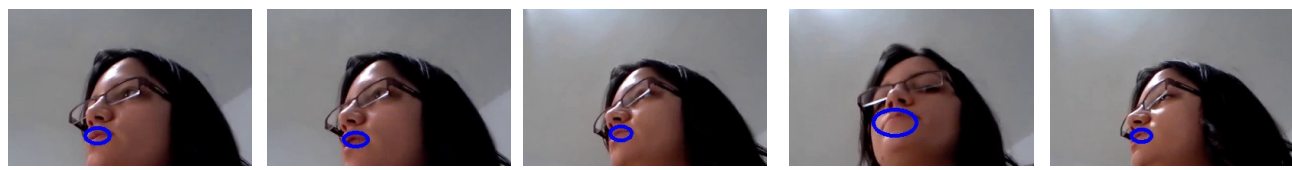

Figura 4.4: Exemplos de detecções em 5 quadros de cada sequência.

\begin{tabular}{|l|l|l|l|l|l|l|}
\hline Detector & TP & FN & FP & Precisão & Revocação & Acurácia \\
\hline D1 & 217 & 86 & 647 & 0,25 & 0,72 & 0,23 \\
\hline D2 & 76 & 227 & 47 & 0,54 & 0,44 & 0,32 \\
\hline
\end{tabular}

Tabela 4.4: Tabela com os valores de precisão, revocação e acurácia para a sequência $S_{r 1}$ com fator de escala de 1,05.

\begin{tabular}{|l|l|l|l|l|l|l|}
\hline Detector & TP & FN & FP & Precisão & Revocação & Acurácia \\
\hline D1 & 187 & 7 & 971 & 0,16 & 0,96 & 0,16 \\
\hline D2 & 30 & 164 & 22 & 0,58 & 0,15 & 0,14 \\
\hline
\end{tabular}

Tabela 4.5: Tabela com os valores de precisão, revocação e acurácia para a sequência $S_{r 2}$ com fator de escala de 1,05.

\begin{tabular}{|l|l|l|l|l|l|l|}
\hline Detector & TP & FN & FP & Precisão & Revocação & Acurácia \\
\hline D1 & 325 & 123 & 1505 & 0,18 & 0,73 & 0,17 \\
\hline D2 & 43 & 405 & 174 & 0,20 & 0,10 & 0,07 \\
\hline
\end{tabular}

Tabela 4.6: Tabela com os valores de precisão, revocação e acurácia para a sequência $S_{r 3}$ com fator de escala de 1,02.

\begin{tabular}{|l|l|l|l|l|l|l|}
\hline Detector & TP & FN & FP & Precisão & Revocação & Acurácia \\
\hline D1 & 0 & 220 & 128 & 0,0 & 0,0 & 0,0 \\
\hline D3 & 105 & 115 & 143 & 0,42 & 0,48 & 0,29 \\
\hline
\end{tabular}

Tabela 4.7: Tabela com os valores de precisão, revocação e acurácia para a sequência $S_{r 4}$ com fator de escala de 1,05. 
A tabela 4.8 mostra o tempo médio da detecção decorrido em todos os quadros das sequências.

\begin{tabular}{|l|l|l|}
\hline Detector & D1 & D2 \\
\hline Sequência 1 & 154,99 & 36,43 \\
\hline Sequência 2 & 187,74 & 40,69 \\
\hline Sequência 3 & 179,79 & 37,20 \\
\hline
\end{tabular}

\begin{tabular}{|l|l|l|}
\hline Detector & D1 & D3 \\
\hline Sequência 4 & 121,40 & 38,63 \\
\hline
\end{tabular}

Tabela 4.8: Tempo médio da deteç̧ão em milissegundos. As sequências 1, 2 e 4 foram testadas com fator de escala 1,05 e a sequência 3 com fator de escala 1,02.

Para as sequências 1 a 3, o detector fornecido pelo OpenCV possui um número maior de acertos, apesar de ser mais lento que o detector D2. A lentidão se deve ao uso do parâmetro fator de escala na função de detecção, que representa a porcentagem em que o tamanho da janela de processamento de características é aumentado a cada varredura da imagem. O fator escolhido para rodar os testes nos dois detectores foi de 1,05 , que significa que a janela é aumentada de $5 \%$ a cada varredura. $\mathrm{Na}$ sequência 3, o fator escolhido foi de 1,02, devido à baixa resolução. O tempo de detecção do D1 será menor caso seja usado um fator de escala maior, como 1,2 ou 1,3.

Para a sequência 4, o detector D3 tem um número maior de acertos que o D1.

Uma hipótese para o desempenho do detector D2 é a influência da cor do interior da boca, que não é mapeado com texturas reais, e possui a mesma cor do plano de fundo. Então o treinamento com imagens sintéticas pode apresentar limitações.

Com relação aos falsos positivos, é necessário o uso de uma verificação rápida na ROI detectada e considerar apenas a maior detecção, ignorando as restantes, apesar da possibilidade de que a maior detecção seja um falso positivo.

\subsection{Rastreamento}

O uso apenas de detecção em todos os quadros mostra que o sistema, sem informação temporal de quadros anteriores, é suscetível a falsos positivos e a descontinuidades (a detecção não ocorre em todos os quadros). O uso de rastreamento pode aumentar a robustez do sistema de detecção, ao fornecer informação dos quadros anteriores para o quadro atual. A figura 4.5 mostra uma amostra de rastreamento de 5 quadros de cada sequência.

\begin{tabular}{|l|l|l|l|l|l|l|}
\hline Sequência & TP & FN & FP & Precisão & Revocação & Acurácia \\
\hline 1 & 263 & 0 & 0 & 1 & 1 & 1 \\
\hline 2 & 104 & 51 & 15 & 0,87 & 0,67 & 0,61 \\
\hline 3 & 84 & 355 & 355 & 0,19 & 0,19 & 0,11 \\
\hline 4 & 152 & 18 & 18 & 0,89 & 0,89 & 0,81 \\
\hline
\end{tabular}

Tabela 4.9: Tabela com os valores de precisão, revocação e acurácia para as sequências.

Para as sequências testadas, caso não ocorra movimentos bruscos ou oclusão, o sistema consegue acompanhar a ROI dos lábios na maioria dos quadros. Ocasionalmente há desvios da ROI nas sequências apresentadas, com exceção da primeira sequência, que se mantém estável. Das sequências apresentadas, a sequência 3 apresentou um desempenho inferior no rastreamento, pois a área rastreada oscilou bastante, em termos de tamanho e posição, chegando a cobrir metade do rosto. Isso se deve à qualidade do vídeo, da resolução e das condições do ambiente. 

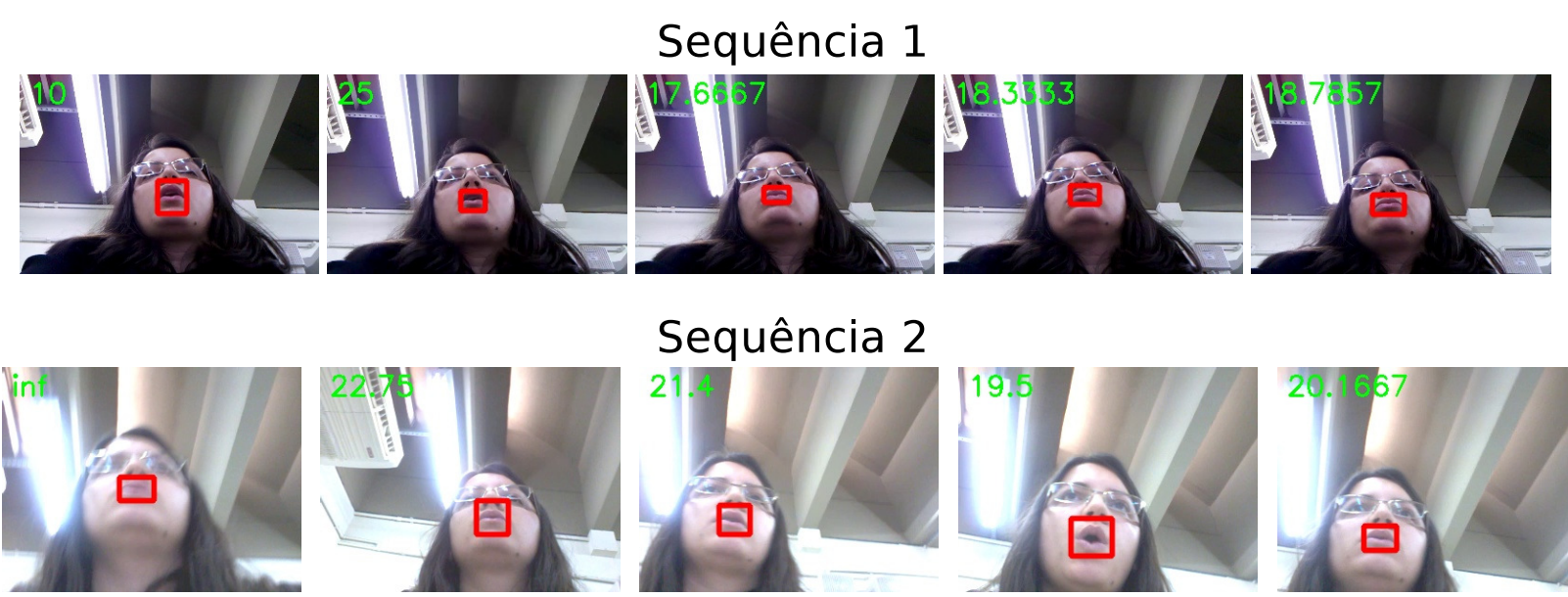

Sequência 2

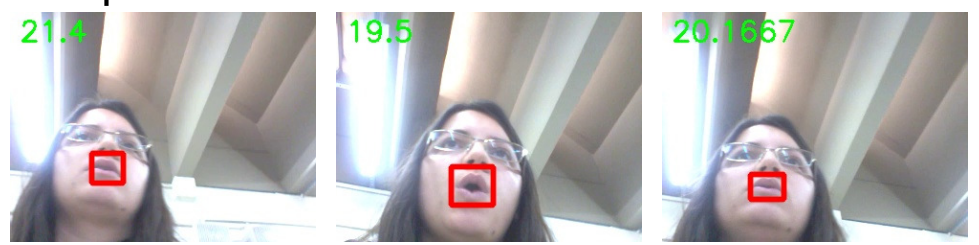

\section{Sequência 3}
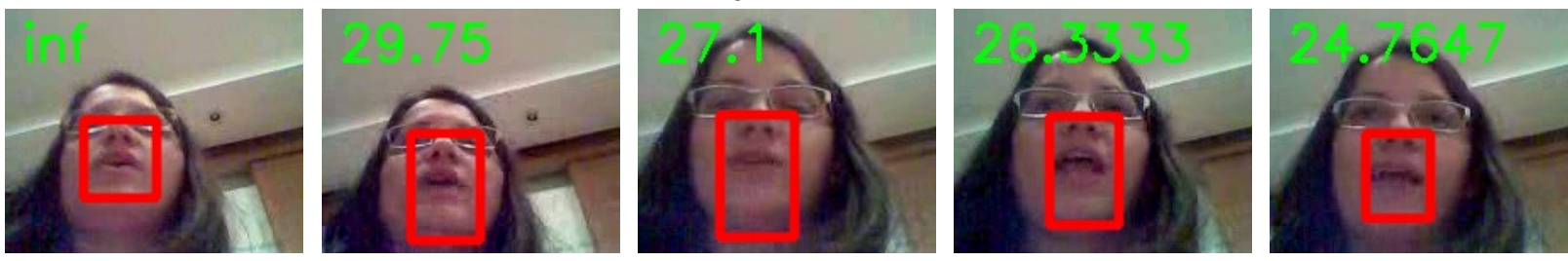

\section{Sequência 4}
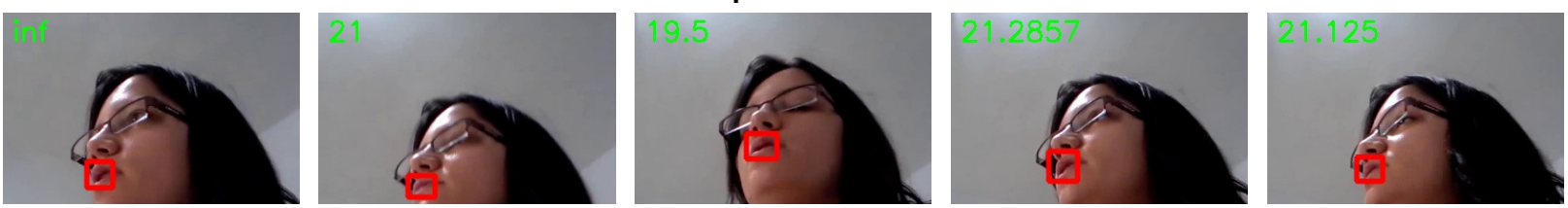

Figura 4.5: Exemplos de rastreamento em 5 quadros de cada sequência.

Para uma análise quantitativa, consideramos novamente o uso de precisão, revocação, acurácia e IOU para as sequências, como mostrado na tabela 4.9. É contabilizado como acerto (TP) se a razão IOU for maior que 0,3 .

A tabela 4.3 mostra a taxa de quadros por segundo (fps - frame per second) para o uso apenas de detecção e o uso combinando detecção e rastreamento.

\begin{tabular}{|l|l|l|l|}
\hline Vídeo & Fps original & $\begin{array}{l}\text { Detecção Apenas } \\
\text { (em fps) }\end{array}$ & $\begin{array}{l}\text { Detecção + Rastreamento } \\
\text { (em fps) }\end{array}$ \\
\hline Sequência 1 & 25 & 13,72 & 17,28 \\
\hline Sequência 2 & 25 & 15,50 & 22,41 \\
\hline Sequência 3 & 30 & 17,98 & 26,84 \\
\hline Sequência 4 & 25 & 15,55 & 18,01 \\
\hline
\end{tabular}

Conclui-se que o uso de rastreamento aumenta a taxa de quadros por segundo, além de garantir uma continuidade, ou seja, acompanhamento da maior parte dos quadros, quando possível. Isso contrasta com a detecção em todos os quadros, que pode ser descontínua e estar sujeita a falsos positivos. 


\subsection{Implementação em um dispositivo móvel}

Os resultados mencionados até o presente momento foram obtidos em um laptop, com sequências gravadas pelo dispositivo móvel. Esta seção mostra os resultados preliminares para uma implementação no dispositivo móvel mencionado no início do capítulo, o Samsung Galaxy S2. A implementação foi feita na linguagem Java em conjunto com a biblioteca OpenCV, que também oferece suporte para o desenvolvimento móvel.

Os quadros capturados pelo dispositivo móvel estão na resolução de 640x480, que é ajustada para 320x240 na etapa de rastreamento para minimizar os custos computacionais. Na etapa da detecção, a taxa fps varia de 8 a $10 \mathrm{fps}$, enquanto na etapa do rastreamento, vai de 4 a 5 fps. A figura 4.6 mostra as imagens capturadas pelo dispositivo móvel em tempo real.

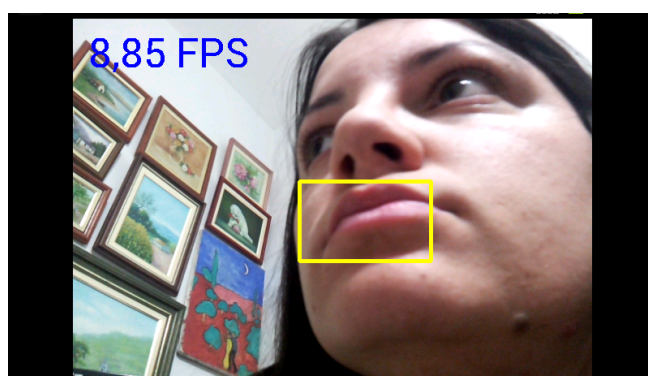

(a)

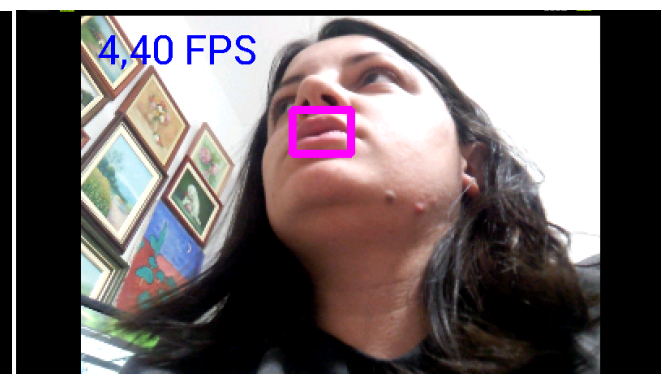

(b)

Figura 4.6: Imagens capturadas do dispositivo móvel. (a) Um exemplo de detecção do detector D3 e (b) rastreamento em um dos quadros subsequentes à detecção.

Dos três detectores testados, todos apresentaram falsos positivos e falsos negativos nas mais diversas condições de iluminação. No caso em que a boca esteja em uma posição frontal e estável, o detector D1 apresenta relativamente o melhor desempenho enquanto o detector D3 realiza algumas detecções em posições da face rotacionada nas quais o detector D1 não realizou detecções.

A ocorrência de falsos positivos se deve ao fato de não se realizar nenhuma verificação sobre a validade da ROI. No momento o aplicativo considera apenas a maior detecção, apesar da possibilidade de ser um falso positivo.

O sucesso da etapa de rastreamento depende da etapa da detecção. Caso a ROI repassada pelo detector seja a boca, o rastreador consegue fazer um acompanhamento razoável da ROI, mesmo com pequenas rotações da face. Em caso de oclusão, há a ocorrência de rastreamento incorreto.

\subsection{Discussão dos resultados}

Os resultados mostrados na etapa de detecção mostram que o uso do método de Viola-Jones pode ser empregado com sucesso em situações específicas dos lábios. O desempenho variável dos detectores treinados mostra que a ausência de elementos internos da boca (dentes e língua) influencia negativamente no treinamento dos detectores, causando overfitting e realizando detecções apenas quando a boca está fechada (detector D2) ou aberta (detector D3).

Com relação aos tempos médios da detecção, o fato dos detectores D2 e D3 serem mais rápidos que o D1 é devido ao conjunto de características Haar ser mais simples, mas ainda assim suficiente para uma discriminação do objeto-alvo. 
O treinamento de características Haar deveria ser feito de modo a criar dois detectores simultaneamente, um para a boca fechada e outro para a boca aberta. Isto é devido ao conjunto de características Haar de uma boca fechada ser diferente do conjunto de uma boca aberta.

Para a validação dos resultados, o uso de sequências de animações a partir de texturas de pessoas reais é válido, mas necessita de complementação de um conjunto de banco de dados de vídeos reais de pessoas. Os bancos de dados atuais não fornecem imagens nas posições simuladas, o que justifica o uso das animações, pela possibilidade de se definir o ponto de vista a partir do dispositivo móvel.

Em relação aos falsos positivos, é desejável o uso de um método de verificação rápida na ROI detectada. Usualmente considerar a maior detecção é suficiente em boa parte dos casos, mas pode não se aplicar a situações específicas, principalmente em tempo real, como no aplicativo móvel.

O rastreamento mostrou ser um complemento necessário à detecção, pois os resultados da detecção só ocorrem em alguns quadros. Em algumas sequências o método acompanhou sem grandes oscilações a ROI. No entretanto nas situações em que há ocorrência de objetos de cor vermelha que não sejam os lábios, o desempenho do rastreador pode degradar, devido ao peso que o espaço YIQ dá à cor vermelha não apenas nos lábios mas também nos objetos que apresentam a cor vermelha pura. Os tempos de processamento na etapa de rastreamento reforçam seu uso, já que a realização de uma detecção em todos os quadros pode ser dispendiosa, enquanto que no rastreamento é desprezível em termos computacionais.

Após os experimentos, conclui-se que é desejável reaplicar a detecção assim que a ROI do rastreio é perdida ou após um certo número de quadros, para calibração. Deste modo, reforça-se a necessidade de uma validação da ROI na etapa de detecção, pois experimentos mostraram alguns falsos positivos após a reaplicação da detecção depois da perda da ROI no rastreio.

Os resultados da implementação do aplicativo móvel mostraram que, devido às condições diversas do ambiente, o método de detecção não teve o desempenho desejado. Apesar da normalização na intensidade máxima reduzir os efeitos da iluminação, não os elimina completamente. Quando à etapa de rastreamento, mostrou um desempenho adequado desde que a ROI entregue pela etapa da detecção seja a correta. Deste modo, a eficácia do rastreamento está diretamente relacionada à detecção correta. 


\section{Capítulo 5}

\section{Conclusão}

\subsection{Comentários finais}

O presente trabalho apresentou um sistema de detecção e rastreamento de lábios para uso em dispositvos móveis em aplicações particulares nas quais a face não se encontra em uma posição frontal. A captura de vídeo ocorre em uma configuração inclinada da posição. Como visto nas seções iniciais, o uso de dispositivos móveis pode beneficiar um grupo de pessoas em particular, os portadores de necessidades especiais, para navegação e extração de informações do ambiente e das pessoas ao redor. O trabalho também apresentou o uso de sequências sintéticas, que é particularmente importante para facilitar a formação de conjuntos de treinamento e anotações de groundtruth para avaliação de performance.

Para a detecção existem vários métodos e nesta dissertação é usado o popular algoritmo de Viola-Jones, por ser eficiente e rápido. Para o treinamento do detector, são usadas imagens sintéticas com rotulações automáticas, eliminando assim a necessidade de rotular manualmente potenciais milhares de imagens positivas para o treino. Assim, a etapa de treinamento é efetuada em um tempo menor que o habitual. Assim enfatiza-se a importância das sequências sintéticas para facilitar a formação de conjuntos de treinamento e anotações de groundtruth para avaliação de performance. Além disso, são abertas possibilidades para treinar detectores de outras características faciais, como detectores de olhos e nariz.

Na etapa do rastreamento, como o foco é rastrear uma região, neste caso, a boca, é usado o Camshift. Como o Camshift original foi inicialmente feito para o rastreamento de faces, são feitas modificações para otimização do método, rastreando especificamente a região dos lábios.

Os métodos propostos neste trabalho foram implementados e testados tanto em um laptop como em um dispositivo móvel rodando Android, com o auxílio da biblioteca OpenCV. Para posições próximas à face frontal, o método atual consegue um desempenho razoável e não muito inferior ao detector-padrão do OpenCV. Em contrapartida, para posições com rotações acentuadas, como uma posição intermediária entre a frontal e a de perfil, o detector proposto nesta dissertação e treinado com imagens sintéticas com rotações semelhantes teve um desempenho relativamente melhor que o detector clássico do OpenCV, apesar de não realizar as detecções em todos os quadros. No caso do rastreamento, o desempenho se mostrou variável. Para posições sem grandes variações da face frontal e com boas condições de iluminação do ambiente, o rastreamento se mostra razoável. Em ambientes com uma iluminação e resolução deficiente ou com a presença de outros objetos com cor 
acentuadamente vermelha, o desempenho decai, chegando a englobar a área da face ou uma região incorreta.

Ainda assim, os resultados da detecção mostram que o treinamento de conjunto de imagens sintéticas é viável e com a ampliação do conjunto, englobando diversas rotações, é possível incrementar mais ainda o desempenho.

\subsection{Trabalhos futuros}

Com os resultados obtidos neste projeto de mestrado, verificou-se que há possibilidades de melhorias tanto na detecção como no rastreamento. No caso da detecção, há a possibilidade de mesclar rotações incrementais do rosto nas animações, nos três eixos espaciais para a geração de um conjunto de treinamento. Isso permite o treinamento de um detector que aumente as possibilidades de deteç̧ão em diversas posições. Nas animações, além dos marcadores de posições dos lábios, também há marcadores em outras características faciais, como os olhos e o nariz, o que abre possibilidades de treino de detectores dessas outras características faciais. Também se estuda a possibilidade de utilizar imagens sintéticas com animações no interior da boca, para melhoria do desempenho e diminuição da influência da ausência do interior da boca que contém a mesma cor do plano de fundo. Após a detecção, são estudadas possibilidades de uma verificação rápida da ROI, para diminuir a ocorrência de falsos positivos. Uma possibilidade é o uso do espaço YIQ também na etapa de detecção, sendo assim uma metodologia simples para descartar ou considerar adequada a ROI detectada.

Em relação ao rastreamento, para uma maior robustez contra oclusões e perdas, estuda-se a possibilidade de usar o filtro de Kalman ou o filtro de partículas, além de intercalar com a detecção em intervalos de um determinado número de quadros. São estudadas alternativas para lidar com a presença de outros objetos com cor vermelha, como o uso de máscaras para vermelho puro e reconhecimento da forma.

Por fim, os resultados podem ser usados como um front-end para um sistema de leitura labial básico em português, em um celular Android. 


\section{Referências Bibliográficas}

Bouvier et al.(2007) C. Bouvier, P.-Y. Coulon e X. Maldague. Unsupervised lips segmentation based on roi optimisation and parametric model. Em Image Processing, 200\%. ICIP 2007. IEEE International Conference on, volume 4, páginas IV-301-IV-304. Citado na pág. 8

Bradski(1998) Gary R. Bradski. Computer vision face tracking for use in a perceptual user interface. Interface, 2(2):12-21. Citado na pág. 20

Castrillón-Santana et al.(2008) Modesto Castrillón-Santana, L. Antón-Canalís O. Déniz-Suárez e J. Lorenzo-Navarro. Face and facial feature detection evaluation. Em Third International Conference on Computer Vision Theory and Applications, VISAPP08. Citado na pág. 29

Cheng(1995) Yizong Cheng. Mean shift, mode seeking, and clustering. IEEE Trans. Pattern Anal. Mach. Intell., 17:790-799. ISSN 0162-8828. Citado na pág. 20

Cherniavsky et al.(2009) Neva Cherniavsky, Jaehong Chon, Jacob O. Wobbrock, Richard E. Ladner e Eve A. Riskin. Activity analysis enabling real-time video communication on mobile phones for deaf users. Em Proceedings of the 22nd annual ACM symposium on User interface software and technology, UIST '09, páginas 79-88, New York, NY, USA. ACM. ISBN 978-160558-745-5. doi: 10.1145/1622176.1622192. URL http://doi.acm.org/10.1145/1622176.1622192. Citado na pág. 5

Dargham e Chekima(2006) J.A. Dargham e A. Chekima. Lips detection in the normalised rgb colour scheme. Em Information and Communication Technologies, 2006. ICTTA '06. 2nd, volume 1, páginas 1546-1551. Citado na pág. 24

Estellers e Thiran(2012) Virginia Estellers e Jean-Philippe Thiran. Multi-pose lipreading and audio-visual speech recognition. EURASIP Journal on Advances in Signal Processing, 2012(1): 51. ISSN 1687-6180. doi: 10.1186/1687-6180-2012-51. URL http://asp.eurasipjournals.com/ content $/ 2012 / 1 / 51$. Citado na pág. 2, 8

Eveno et al.(2004) N. Eveno, A. Caplier e P.-Y. Coulon. Accurate and quasi-automatic lip tracking. Circuits and Systems for Video Technology, IEEE Transactions on, 14(5):706-715. Citado na pág. 7

Fisher(1968) Cletus G. Fisher. Confusions among visually perceived consonants. J Speech Hear Res, 11(4):796-804. Citado na pág. 1

Freund e Schapire(1997) Yoav Freund e Robert E. Schapire. A decision-theoretic generalization of on-line learning and an application to boosting, 1997. Citado na pág. 14

Guitarte Perez et al.(2005) J.F. Guitarte Perez, A.F. Frangi, E. Lleida Solano e K. Lukas. Lip reading for robust speech recognition on embedded devices. Em Acoustics, Speech, and Signal Processing, 2005. Proceedings. (ICASSP '05). IEEE International Conference on, volume 1, páginas 473-476. Citado na pág. 7, 8 
Hsu et al.(2002) Rein-Lien Hsu, M. Abdel-Mottaleb e A. K. Jain. Face detection in color images. Pattern Analysis and Machine Intelligence, IEEE Transactions on, 24(5):696-706. Citado na pág. 7

Hurlbert e Poggio(1988) A. C. Hurlbert e T. Poggio. Synthesizing a color algorithm from examples. Science, 239:482-485. Citado na pág. 7

Kalal et al.(2009) Z. Kalal, J. Matas e K. Mikolajczyk. Online learning of robust object detectors during unstable tracking. Em Computer Vision Workshops (ICCV Workshops), 2009 IEEE 12th International Conference on, páginas 1417-1424. Citado na pág. 9

Kalal et al.(2010a) Zdenek Kalal, Krystian Mikolajczyk e Jiri Matas. Face-tld: Tracking-learningdetection applied to faces. Image Processing ICIP 2010 17th IEEE International Conference on, páginas 3789-3792. Citado na pág. xi, 10

Kalal et al.(2010b) Zdenek Kalal, Krystian Mikolajczyk e Jiri Matas. Face-tld (poster). IEEE. Citado na pág. xi, 10

Kim et al.(2009) Young-Un Kim, Sun-Kyung Kang e Sung-Tae Jung. Design and implementation of a lip reading system in smart phone environment. Em Proceedings of the 10th IEEE international conference on Information Reuse $\mathcal{E}$ Integration, IRI'09, páginas 101-104, Piscataway, NJ, USA. IEEE Press. ISBN 978-1-4244-4114-3. URL http://dl.acm.org/citation.cfm?id=1689250. 1689269. Citado na pág. 7, 8

Kumar et al.(2007) Kshitiz Kumar, Tsuhan Chen e Richard M. Stern. Profile view lip reading. Em 2007 IEEE International Conference on Acoustics, Speech and Signal Processing - ICASSP '07, páginas IV-429-IV-432. IEEE. Citado na pág. 8

Liew e Wang(2008) Alan Wee-Chung Liew e Shilin Wang. Visual Speech Recognition: Lip Segmentation and Mapping. Information Science Reference - Imprint of: IGI Publishing, Hershey, PA. ISBN 1605661864, 9781605661865. Citado na pág. 1, 5

Lucey et al.(2008) Patrick Lucey, Sridha Sridharan e David Dean. Continuous pose-invariant lipreading. Em INTERSPEECH, páginas 2679-2682. Citado na pág. 2, 8

Manduchi e Coughlan(2012) Roberto Manduchi e J. Coughlan. (computer) vision without sight. Communications of the ACM, 44. URL http://cacm.acm.org/magazines/2012/1/ 144819-computer-vision-without-sight/fulltext. Citado na pág. 5

Manduchi et al.(2010) Roberto Manduchi, Sri Hastuti Kurniawan e Homayoun Bagherinia. Blind guidance using mobile computer vision: A usability study. Em ACM SIGACCESS Conference on Computers and Accessibility (ASSETS). Citado na pág. 5

Mattos et al.(2010) Andréa B. Mattos, Jesús P. Mena-Chalco, Luiz Velho e Roberto M. Cesar-Jr. 3d linear facial animation based on real data. XXIII Brazilian Symposium on Computer Graphics and Image Processing - Sibgrapi. Citado na pág. 2, 9, 16

Moreno e Sanchez(2004) AB Moreno e A. Sanchez. Gavabdb: a 3d face database. Em Proc. 2nd COST275 Workshop on Biometrics on the Internet, Vigo (Spain), páginas 75-80. Citado na pág. 8

Ooi et al.(2008) Wei Chuan Ooi, Changwon Jeon, Kihyeon Kim, D.K. Han e Hanseok Ko. Effective lip localization and tracking for achieving multimodal speech recognition. Em Multisensor Fusion and Integration for Intelligent Systems, 2008. MFI 2008. IEEE International Conference on, páginas $90-93$. Citado na pág. 22 
Queiroz et al.(2010) Rossana Queiroz, Marcelo Cohen, Juliano L. Moreira, Adriana Braun, Julio C. Jacques Junior e Soraia Raupp Musse. Generating facial ground truth with synthetic faces. Em Proceedings of the 2010 23rd SIBGRAPI Conference on Graphics, Patterns and Images, SIBGRAPI 2010, páginas 25-31, Washington, DC, USA. IEEE Computer Society. ISBN 978-0-76954230-0. doi: 10.1109/SIBGRAPI.2010.12. URL http://dx.doi.org/10.1109/SIBGRAPI.2010.12. Citado na pág. 9

Seo(2008) Naotoshi Seo. Negatives for haar training, 2008. URL http://tutorial-haartraining. googlecode.com/svn/trunk/data/negatives/. Citado na pág. xi, 17, 19

Shin et al.(2011) Jongju Shin, Jin Lee e Daijin Kim. Real-time lip reading system for isolated korean word recognition. Pattern Recognition, 44(3):559-571. Citado na pág. xi, 7, 8, 9

Tan et al.(2005) Pang-Ning Tan, Michael Steinbach e Vipin Kumar. Introduction to Data Mining, (First Edition). Addison-Wesley Longman Publishing Co., Inc., Boston, MA, USA. ISBN 0321321367. Citado na pág. 31

Tekin et al.(2011) Ender Tekin, James M. Coughlan e Huiying Shen. Real-time detection and reading of led/lcd displays for visually impaired persons. Em Proceedings of the 2011 IEEE Workshop on Applications of Computer Vision (WACV), WACV '11, páginas 491-496, Washington, DC, USA. IEEE Computer Society. ISBN 978-1-4244-9496-5. doi: 10.1109/WACV.2011. 5711544. URL http://dx.doi.org/10.1109/WACV.2011.5711544. Citado na pág. 5

Thejaswi e Sengupta(2008) N. S. Thejaswi e S. Sengupta. Lip localization and viseme recognition from video sequences. Fourteenth National Conference on Communications. Citado na pág. $7,22,25$

Tresadern et al.(2011) P. Tresadern, M. Ionita e T. Cootes. Real-time facial feature tracking on a mobile device. International Journal of Computer Vision, páginas 1-10. Citado na pág. xi, 7, 8, 9

Ukrainitz e Sarel(2004) Yaron Ukrainitz e Bernard Sarel. Mean shift, 2004. URL http://www. wisdom.weizmann.ac.il/ vision/courses/2004_2/files/mean_shift/mean_shift.ppt. Citado na pág. xi, 20

Viola e Jones(2002) Paul Viola e Michael Jones. Robust real-time object detection. International Journal of Computer Vision. Citado na pág. xi, 2, 12, 13, 14

Wang et al.(2010) Lirong Wang, Xiaoli Wang e Jing Xu. Lip detection and tracking using variance based haar-like features and kalman filter. Em Frontier of Computer Science and Technology (FCST), 2010 Fifth International Conference on, páginas 608-612. Citado na pág. 9

Wark et al.(1998) T. Wark, S. Sridharan e V. Chandran. An approach to statistical lip modelling for speaker identification via chromatic feature extraction. Em Pattern Recognition, 1998. Proceedings. Fourteenth International Conference on, volume 1, páginas 123-125 vol.1. Citado na pág. 7

Yilmaz et al.(2006) Alper Yilmaz, Omar Javed e Mubarak Shah. Object tracking: A survey. ACM Comput. Surv., 38(4):13. Citado na pág. 2, 9

Yin et al.(2006) Lijun Yin, Xiaozhou Wei, Yi Sun, Jun Wang e Matthew J. Rosato. A 3d facial expression database for facial behavior research. Em Proceedings of the 7th International Conference on Automatic Face and Gesture Recognition, FGR '06, páginas 211-216, Washington, DC, USA. IEEE Computer Society. ISBN 0-7695-2503-2. doi: 10.1109/FGR.2006.6. URL http: //dx.doi.org/10.1109/FGR.2006.6. Citado na pág. 9 